archives-ouvertes

\title{
Alkylation of uracil and thymine in the gas phase through interaction with alkylmercury compounds
}

Jean-Yves Salpin, Violette Haldys, Latifa Latrous, Jean-Claude Guillemin, Jeanine Tortajada, Emmanuelle Léon, Otilia Mó, Manuel Yáñez, M. Merced Montero-Campillo

\section{To cite this version:}

Jean-Yves Salpin, Violette Haldys, Latifa Latrous, Jean-Claude Guillemin, Jeanine Tortajada, et al.. Alkylation of uracil and thymine in the gas phase through interaction with alkylmercury compounds. International Journal of Mass Spectrometry, Elsevier, 2019, 436, pp.153-165. 10.1016/j.ijms.2018.12.003 . hal-02000335

\section{HAL Id: hal-02000335 \\ https://hal.archives-ouvertes.fr/hal-02000335}

Submitted on 20 Mar 2019

HAL is a multi-disciplinary open access archive for the deposit and dissemination of scientific research documents, whether they are published or not. The documents may come from teaching and research institutions in France or abroad, or from public or private research centers.
L'archive ouverte pluridisciplinaire HAL, est destinée au dépôt et à la diffusion de documents scientifiques de niveau recherche, publiés ou non, émanant des établissements d'enseignement et de recherche français ou étrangers, des laboratoires publics ou privés. 


\section{Alkylation of uracil and thymine in the gas phase through interaction with alkylmercury compounds.}

Jean-Yves Salpin*1,2, Violette Haldys ${ }^{1,2}$, Latifa Latrous ${ }^{3}$, Jean-Claude Guillemin ${ }^{4}$, Jeanine Tortajada ${ }^{1,2}$, Emmanuelle Léon ${ }^{1,2}$, Otilia Mó ${ }^{5,6}$, Manuel Yáñez ${ }^{* 5,6}$, M. Merced Montero-Campillo*5,6

1. LAMBE, CEA, CNRS, Univ Evry, Université Paris-Saclay, F-91025, Evry, France

2. LAMBE, UCP, Université Paris-Seine, F-91025, Evry, France

3. Université de Tunis El Manar, Faculté des Sciences de Tunis, Laboratoire de Chimie Analytique et Electrochimie Campus universitaire 2092, Tunis, Tunisie.

4. Univ Rennes, Ecole Nationale Supérieure de Chimie de Rennes, CNRS, ISCR UMR6226, F-35000 Rennes, France

5. Departamento de Química, Módulo 13. Universidad Autónoma de Madrid. Cantoblanco, Campus de Excelencia UAM-CSIC, 28049-Madrid. Spain.

${ }^{6}$. Institute of Advanced Chemical Sciences (IadChem). Universidad Autónoma de Madrid, Campus de Excelencia UAM-CSIC, Cantoblanco, 28049-Madrid, Spain

\section{Dedicated to Prof. Helmut Schwarz on the occasion of his $75^{\text {th }}$ birthday.}

Number of pages (including Tables, Figures, legends and schemes): 37

*Corresponding authors: Jean-Yves Salpin Tel: $33169477644 \quad$ Fax: 3316947 7655 e-mail : jeanyves.salpin@ univ-evry.fr Manuel Yáñez_Tel: 34914974953 e-mail : manuel.yanez@uam.es,_M. Merced Montero-Campillo Tel: 34914973462 e-mail : mm.montero@uam.es

ORCID

J-Y. Salpin: https://orcid.org/0000-0003-0979-1251

M. Yáñez: https://orcid.org/0000-0003-0854-585X

O. Mó: https://orcid.org/0000-0003-2596-5987

J.-C. Guillemin: https://orcid.org/0000-0002-2929-057X

M. Merced Montero-Campillo: http://orcid.org/0000-0002-9499-0900 


\section{Graphical_Abstracts}

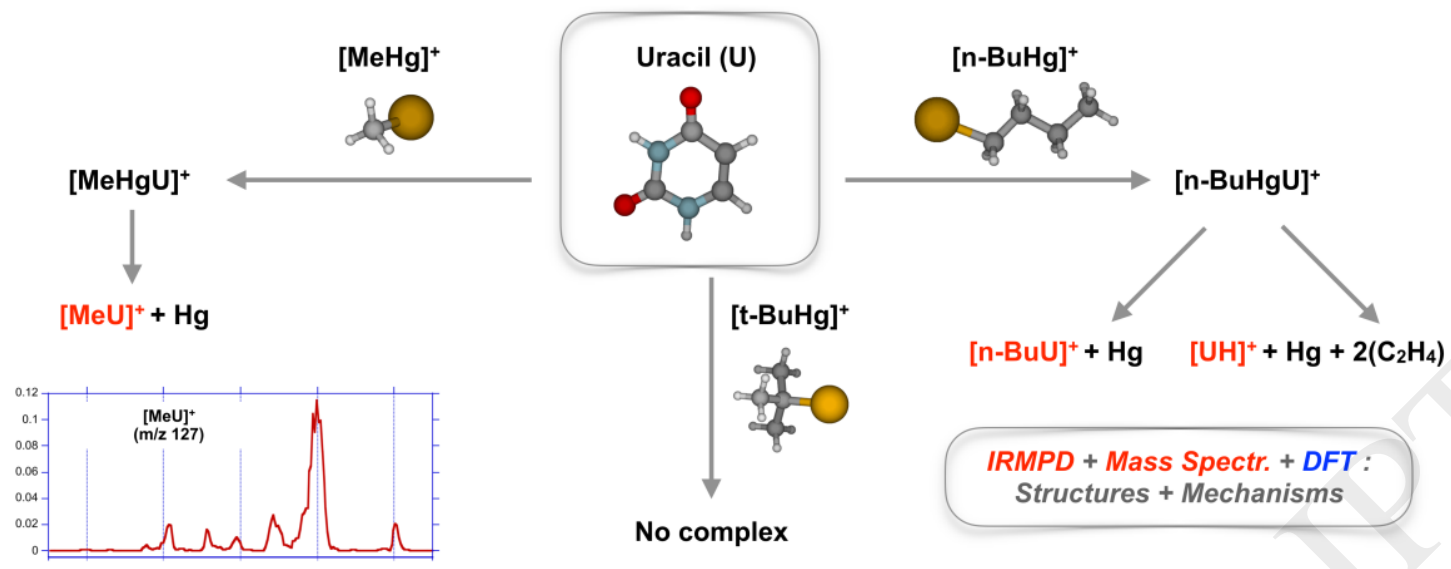

\section{Highlights}

- $[\operatorname{RHg}(\mathrm{NB})]^{+}$ions formed by the gas-phase reaction of Nucleobases with alkylmercury ions leads to the formation of $[\mathrm{NB}] \mathrm{R}^{+}$ions.

- For large alkyl chains (reactions with $\mathrm{n}-\mathrm{BuHg}^{+}$) the protonated nucleobase, $\mathrm{NBH}^{+}$is also produced

- The nature and conformation of the products was established by combining tandem mass spectrometry and IRMPD spectroscopy to DFT calculations.

- The PESs associated to the formation of the main products were explored

\section{Abstract}

The gas-phase interactions of uracil and thymine with alkylmercury cations, in particular $\mathrm{CH}_{3} \mathrm{Hg}^{+}$, n- $\mathrm{BuHg}^{+}$and $\mathrm{t}-\mathrm{BuHg}^{+}$, were studied through the use of electrospray ionization coupled to tandem mass spectrometry. We observed that the interaction of akylmercury compounds with the nucleobases (NB) gives rise to a single type of complex of general formula $[\mathrm{RHg}(\mathrm{NB})]^{+}$, except for t-butyl-mercury (no interaction). The subsequent MS/MS experiments show that the $[\mathrm{RHg}]^{+}$ions $(\mathrm{R}=\mathrm{Me}, \mathrm{n}-\mathrm{Bu})$ exhibit a peculiar reactivity characterized by the transfer of the alkyl group to the nucleobases. Indeed, the main fragmentation process observed leads to the loss of neutral $\mathrm{Hg}$, producing $[(\mathrm{NB}) \mathrm{R}]^{+}$ions. Only when the length of the alkyl chain increases, as in the case of reactions with $[\mathrm{n}-\mathrm{BuHg}]^{+}$, a new fragmentation path is opened, yielding the protonated nucleobase, $[(\mathrm{NB}) \mathrm{H}]^{+}$, with the concomitant elimination of $\mathrm{C}_{4}, \mathrm{H}_{8}, \mathrm{Hg}$. A thorough analysis of the mechanisms behind both dominant processes was carried out 
through the use of Infrared Multiple Photon Dissociation (IRMPD) in the fingerprint region, combined with an analysis of the corresponding potential energy surfaces by using high-level density functional theory (DFT) calculations.

\section{Introduction}

The huge development of mass spectrometry along the second half of the $20^{\text {th }}$ century and the first decades of the $21^{\text {st }}$ century was nicely enhanced by the useful synergy between theory and experiment. Undoubtedly, the different experimental techniques provided more and more precise information about the products and their relative abundance, but still in many instances a complete characterization of the mechanisms connecting reactants with products could only be achieved by the wise combination of the information experimentally obtained and the insights provided by ab initio or density functional theory (DFT) calculations[1, 2]. Helmut Schwarz has been one of the scientists that better exploited this experiment-theory synergy through a large number of papers where a complete picture of the process investigated was provided by rationalizing the experimental findings in the light of appropriate theoretical calculations, from which we would like to highlight some of his most recent works [3-6]. In particular, Schwarz made a significant contribution to the understanding of the alkylation of amines by methylmetal complexes, the metals being $\mathrm{Zn}, \mathrm{Cd}$ and $\mathrm{Hg}[7,8]$. During these last twenty years our groups also adopted this synergy to study a variety of chemical systems involving the interaction of metal ions with organic molecules and biomolecules [9-17]. Notably, we examined in great detail the interactions of uracil and thymine with different metal ions, and compare the unimolecular reactivity observed with copper, [18-20] calcium, [21-24] or heavier metals [25-29]. In the present paper, we extend this survey to study the reactivity occurring in the gas phase in the presence of organomercury compounds. 
The growing anthropologic use of mercury compounds has led to significant environmental contamination. This is a major concern since mercury is one of the most toxic metals[30-33] due to the great solubility of $\mathrm{Hg}(\mathrm{II})$ ions at physiological $\mathrm{pH}$. This high toxicity is also imparted to its organometallic forms $[\mathrm{RHg}]^{+}(\mathrm{R}=\mathrm{alkyl}$ or aryl $)[34,35]$. The methyl-mercury ion, $\mathrm{MeHg}^{+}$, is probably the most ubiquitous compound and, owing to its enhanced solubility in water, is a dangerous pollutant agent. The stability of the $\mathrm{Hg}-\mathrm{C}$ bond plays an important role in the toxicity of alkylmercury compounds, since the nature of the anion associated with the alkylmercury moiety when it enters the body, has little effect on the subsequent metabolic behavior of the compound. Alkyl mercury ions have a strong affinity for thiols and rather quickly become bound to proteins or polypeptide chains, leaving the original anion behind. It has been shown that, for instance, methyl mercury is strongly neurotoxic, affecting the central nervous system.[36] Although the mechanism is not fully understood yet, [37] it was also recently suggested to be related to the inhibition of the Rho-associated protein kinase 1.[38] It is also worth emphasizing that the cleavage of the $\mathrm{Hg}-\mathrm{C}$ bond and the reduction of the mercuric residues to elemental mercury are involved in the response of bacteria to the toxicity of methylmercury chloride [39].

Mercury may cause both neurological and genetic damages, and may express its genotoxicity by different mechanisms. Some are indirect. For example, $\mathrm{Hg}^{2+}$ ions promote the formation of reactive oxygen species (ROS)[40-42] and can also disrupt DNA repair processes $[43,44]$. On the other hand, other mechanisms result from the direct interaction with DNA. It has been hypothesized that DNA double helix interactions with different mercury compounds $\left(\mathrm{Hg}^{2+},[\mathrm{RHg}]^{+}\right)$occur [45]. When interacting with DNA, mercury compounds also seem to exhibit a strong affinity for the thymine residues [46]. However, the detailed structure of adducts formed between $[\mathrm{RHg}]^{+}$compounds and DNA has yet to be determined. Gas-phase studies may provide useful insights about the mechanisms 
occurring at the molecular level between $\mathrm{Hg}$ (II) species and DNA building blocks. In this context, we presently report a combined experimental and theoretical study about the interactions taking place in the gas phase between a series of cations arising from alkylmercury chlorides and two nucleobases, uracil and thymine. Our results show that $[\mathrm{RHg}]^{+}$ions $\left(\mathrm{R}=\mathrm{CH}_{3}, \mathrm{n}-\mathrm{Bu}\right)$ exhibit a peculiar reactivity characterized by the transfer of the alkyl group to the nucleobases. Tandem mass spectrometry, Infrared Multiple Photon Dissociation and DFT calculations were combined in order to decipher the structure of both the complexes and the alkylated nucleobases, and to propose mechanisms accounting for the ions observed experimentally.

\section{Methodology}

\section{a) Mass spectrometry.}

MS and MS/MS spectra were recorded on a triple-quadrupole instrument (Applied Biosystems/MDS Sciex API 2000), the ions being generated in the gas phase by an electrospray (ESI) source ("turboionspray"). A solution mixture of alkylmercury chloride/nucleobase $\left(210^{-4} \mathrm{M} / 10^{-4} \mathrm{M}\right.$ in $50 / 50$ methanol/milli-Q water) was infused in the source with a syringe pump. The ESI conditions were as follows: flow rate: $300 \mu \mathrm{l} / \mathrm{h}$; sprayer probe voltage: $3.8-5.0 \mathrm{kV}$; pressure of GAS1 (nebulizing gas, air): 2.1 bars; pressure of GAS2 (air): 2.1 bars, temperature of GAS2: $100^{\circ} \mathrm{C}$; pressure of curtain gas $\left(\mathrm{N}_{2}\right)$ : 1.4 bars.

In order to record low-energy CID spectra, precursor ions were selected by the first mass filter (Q1), then were allowed to collide with nitrogen in the collision cell (Q2), at different collision energies. Finally, the fragment ions were analyzed by the second mass filter (Q3). The collision energy was varied from 5 to $20 \mathrm{eV}$ (laboratory frame) (the collision energy is set by adjusting the difference of potentials between Q0 and Q2). MS/MS spectra were carried out by introducing nitrogen as collision gas in the second quadrupole at a total 
pressure of $3 \times 10^{-5}$ mbar, the background pressure being around $10^{-5}$ mbar as measured by the ion gauge located outside the collision cell. The actual pressure inside the collision cell being of several mTorr[47], MS/MS spectra are very likely obtained under a multiplecollision regime as discussed in previous work [48].

\section{b) Infrared multiple photon dissociation (IRMPD) spectroscopy.}

During the present IRMPD experiments, the fingerprint region $\left(900-1900 \mathrm{~cm}^{-1}\right)$ has been explored using the beamline of the free electron laser (FEL) of the Centre Laser Infrarouge d'Orsay (CLIO) [49]. The FEL beamline (electron energy set at $44 \mathrm{MeV}$ ) was coupled to a Bruker quadrupole ion trap (Esquire 3000+). This coupling has been extensively described in previous works. [50-52]

The complex of interest has been obtained as gaseous species by ESI of a water/methanol solution prepared as described previously (vide supra). The ESI source parameters were set as follows: flow rate: $180 \mu \mathrm{l} / \mathrm{h}$; spray voltage: $4.5 \mathrm{kV}$; temperature of the transfer capillary: $200{ }^{\circ} \mathrm{C}$.

The Bruker Esquire Control (v5.2) software was used to record the IRMPD spectra. To this end, complexes of interest (or the first generation of fragment ions) were first isolated and then irradiated for 200-1000 ms (with or without attenuation, depending on the ion) during the MS2 (MS3) step, the excitation amplitude being concomitantly set to 0 to avoid any CID-like process. Mass spectra were acquired according the following conditions: accumulation time: $25 \mathrm{~ms}$; number of accumulations: 10; $\mathrm{m} / \mathrm{z}$ range: 50-3000; scan resolution: $13000 \mathrm{Th} / \mathrm{s}$. This acquisition cycle was repeated ten times before changing the photon wavelength.

IRMPD spectra are obtained by plotting the photofragmentation yield $\mathrm{R}(\mathrm{R}=$ $\left.\ln \left[\mathrm{I}_{\text {precursor }} /\left(\mathrm{I}_{\text {precursor }}+\Sigma \mathrm{I}_{\text {fragments }}\right)\right]\right)$, where $\mathrm{I}_{\text {precursor }}$ and $\mathrm{I}_{\text {fragments }}$ are the integrated intensities 
of the mass peaks of the precursor and of the fragment ions, respectively, as a function of the frequency of the IR radiation.

All the $\mathrm{m} / \mathrm{z}$ values discussed in the text correspond to ions incorporating the dominant ${ }^{202} \mathrm{Hg}$ isotope. All the nucleobases and methanol used in this work were purchased from Sigma-Aldrich (Saint-Quentin Fallavier, France) and were used without further purification.

\section{c) Synthesis.}

Methyl, n-butyl, and tert-butylmercury chloride have been synthesized as previously reported starting from methyl magnesium chloride, n-butylmagnesium chloride and tbutylmagnesium chloride, respectively[53].

\section{d) Computational details.}

Pyykkö and Desclaux established in the late seventies the crucial role of relativistic effects on the high stability of $\mathrm{Hg}^{2+}$ and the inertness of $\mathrm{Hg}$ [54]. However, ab initio methods accounting for these effects are prohibitively expensive for systems of the size explored in this paper. In the late nineties, it was shown that DFT calculations provided similar conclusions to other $a b$ initio formalisms as far as the structural and energetic properties of $\mathrm{HgF}_{4}$ were concerned. [55] G. Malli also found 2-component DFT to provide bonding and energetics of superheavy roentgenium derivatives, similar to ab initio methods [56]. The method used in our theoretical survey was chosen by taking into consideration a previous assessment of a large set of density functional methods and an ample set of basis sets for the treatment of $\mathrm{Hg}$ containing systems[57]. The functionals included in that assessment were three non-hybrid functionals, namely BLYP[58], M06-L[59] and BP86[60], a GGA functional, B97-D[61], which includes corrections for dispersion; six hybrid functionals, namely M06[62], B3LYP[63, 64], X3LYP[65], PBE0[66], MPW1PW91[67] and 
B3PW91[68], one long-range corrected functional (LC-BLYP)[69] and a double hybrid (B2PLYP)[70] one. Also the following basis sets for Hg, LANL2DZ, MWB60, cc-PVTZPP, DEF2-TVZPP, DEF2-TVZPPD, taken from the EMSL basis set library[71, 72] were analyzed. In this assessment,[57] it was concluded that B3LYP was the functional which provides the smallest average error, when used in association with a DEF2-TVZPPD basis set for $\mathrm{Hg}$, which includes an effective small core pseudopotential to account for the relativistic effects non-negligible for this element, for the description of the infrared spectra of the compounds investigated, as well as other physicochemical properties, such as ionization energies and binding energies. For this reason, we consider that this DFT approach was proved to provide accurate results when compared to experimental results, although relativistic effects might be relevant in some particular cases.

Consequently, in this paper the equilibrium geometries of the complexes of uracil with $\left[\mathrm{CH}_{3} \mathrm{Hg}\right]^{+}$and $[\mathrm{n}-\mathrm{BuHg}]^{+}$were obtained through the use of the B3LYP functional together with a TVZPPD valence basis for $\mathrm{Hg}$ and a $6-31++\mathrm{G}(\mathrm{d}, \mathrm{p})$ basis set for the remaining atoms of the system. The same level of theory, i.e. B3LYP/6-31++G(d,p) was used to optimize the structures of the corresponding neutrals. The harmonic vibrational frequencies were calculated at the same levels of theory used for the geometry optimizations, in order to classify the stationary points of the potential energy surfaces (PESs) as minima or transition states and to obtain the corresponding rotational and vibrational corrections to estimate final enthalpies. The electronic final energies were obtained in single point calculations on the aforementioned optimized geometries but using a quadruple zeta (QZVPD) basis set expansion for $\mathrm{Hg}$ atom and a $6-311+\mathrm{G}(3 \mathrm{df}, 2 \mathrm{p})$ basis set for the remaining atoms of the system. Concerning the comparison between IRMPD and DFT-computed vibrational spectra, the latter were scaled by a factor of 0.97 and for 
ease of comparison with the experimental spectrum, calculated spectra were convoluted with a $15 \mathrm{~cm}^{-1}$ gaussian function.

The analysis of the electron density distribution of some critical structures along the PES was carried out by means of the Bader's atoms in molecules theory [73, 74]. For this purpose, the topology of the electron density, calculated at the same level used for the geometry optimizations, was analyzed to locate the corresponding bond and ring critical points. The values of the electron density and energy density at these points provide useful information about the strength and the nature of the interactions between the different atoms of the system.

\section{Results}

a) MS and MS/MS study

In order to study the interactions taking place between the cations derived from alkylmercury compounds and the uracil and thymine nucleobases, we used electrospray ionization coupled to tandem mass spectrometry. A series of electrospray mass spectra were acquired by scanning the cone voltage (that is the declustering potential for our triplequadrupole instrument) from 0 to $80 \mathrm{~V}$. The interaction of akylmercury compounds with the nucleobases (NB) gives rise to a single type of complex of general formula $[\mathrm{RHg}(\mathrm{NB})]^{+}$, resulting from the simple addition of the $[\mathrm{RHg}]^{+}$moiety onto the nucleobase. Their intensity is significant albeit low, and quickly drops as the cone voltage is increased. In the presence of uracil, this leads to ions observed at $m / z, 329$ and 371 with $\mathrm{CH}_{3} \mathrm{HgCl}$ and $\mathrm{n}$ - $\mathrm{BuHgCl}$, respectively, these complexes being shifted by 14 mass units in presence of thymine. On the other hand, in spite of the many attempts, by changing the solvent conditions or the metal/nucleobase ratio, no complex has been observed when using the tert-butyl-mercury chloride. Mercury-containing ions are easily identified due to the 
specific isotopic distribution of this metal, resulting in characteristic isotopic profiles (see insert in Figure 1). The isotopic profiles also confirm the lack of any chloride atom.

In order to describe the unimolecular reactivity of the complexes observed, we performed a series of MS/MS experiments, including in source fragmentations followed by MS/MS spectra of fragments ions, use of labeled compounds and selection of several mercury isotopes. MS/MS spectra were recorded at different collision energies between 2 to $20 \mathrm{eV}$ in the laboratory frame. Typical MS/MS spectra of the $\left[\mathrm{CH}_{3} \mathrm{Hg} \text { (uracil) }\right]^{+}(\mathrm{m} / z$ 329) and [n$\operatorname{BuHg}($ uracil $)]^{+}(m / z \quad 371)$ complexes are reported in Figure 1. The set of MS/MS experiments performed resulted in the dissociation pattern summarized in Scheme 1 and in Table 1. 


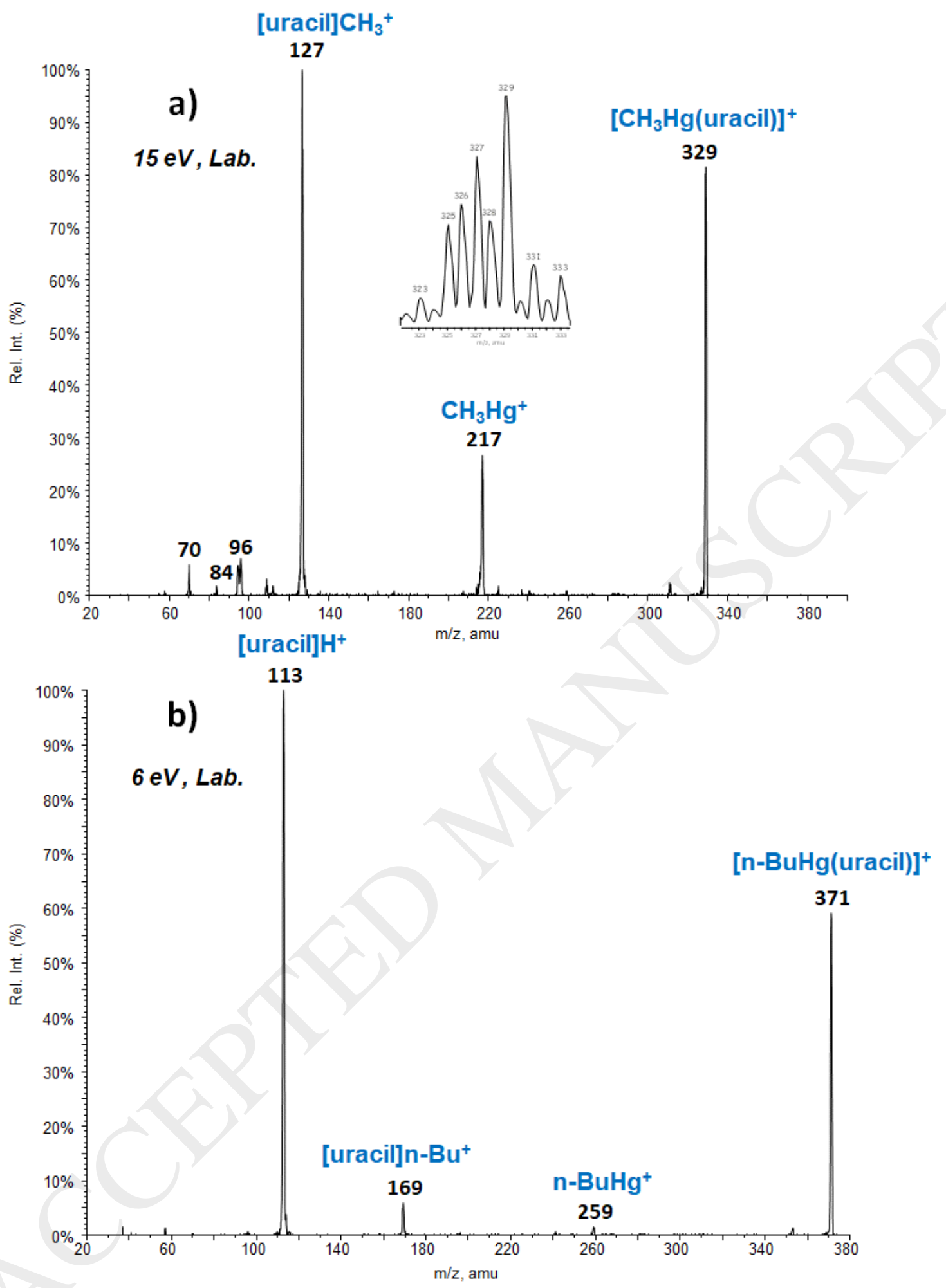

Figure 1 : low-energy $\mathrm{MS} / \mathrm{MS}$ spectra of a) $\left[\mathrm{CH}_{3} \mathrm{Hg} \text { (uracil) }\right]^{+}$and b) $[\mathrm{n}-\mathrm{BuHg} \text { (uracil) }]^{+}$complexes generated under electrospray conditions. In insert the isotopic distribution observed for the $\left[\mathrm{CH}_{3} \mathrm{Hg}(\text { uracil })\right]^{+}$ion on the ESI spectrum. 


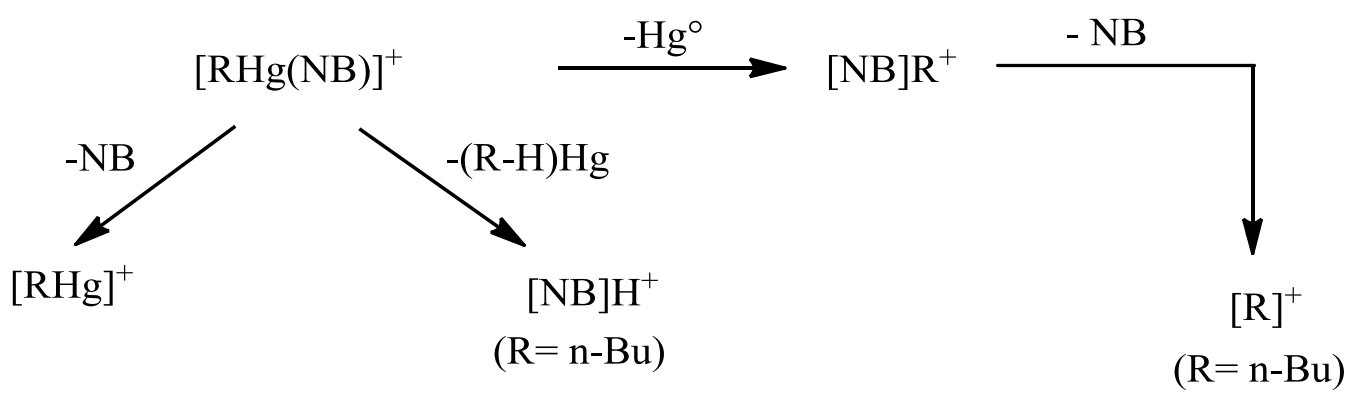

Scheme 1: fragmentation pattern of the $[\mathrm{RHg}(\mathrm{NB})]^{+}$complexes.

The unimolecular reactivity of the $\left[\mathrm{CH}_{3} \mathrm{Hg}(\mathrm{NB})\right]^{+}$complex is characterized by two distinct processes. The first one corresponds to the elimination of the nucleobase, leading to $\left[\mathrm{CH}_{3} \mathrm{Hg}\right]^{+}(\mathrm{m} / 2$ 217). The second and very characteristic process is the transfer of the alkyl group to the nucleobases, leading to $[(\mathrm{NB}) \mathrm{R}]^{+}$ions through loss of $\mathrm{Hg}^{\circ}$. This is the prominent process observed with methyl mercury chloride (Figure 1a). Lengthening the alkyl chain opens a new fragmentation pathway leading to the protonation of uracil or thymine and the concomitant elimination of $\mathrm{C}_{4}, \mathrm{H}_{8}, \mathrm{Hg}$ (Figure 1b). Proton transfer to the nucleobase is theoretically already feasible with an ethyl chain through a $\beta$-hydride elimination mechanism. Besides this latter process, the length and flexibility of the n-Butyl chain opens up alternative pathways, like those described in the following sections. Finally, an additional fragment ion arises from $[(\mathrm{NB}) n-\mathrm{Bu}]^{+}$and corresponds to the $\mathrm{C}_{4} \mathrm{H}_{9}{ }^{+}$ carbocation $(\mathrm{m} / \mathrm{z}, 57)$. Formation of the $\left[\mathrm{CH}_{3}\right]^{+}$is not observed, probably because of the high heat of formation of this species. In Figure 1a, the ions observed in low abundance below $\mathrm{m} / \mathrm{z} 100$ come from the subsequent fragmentation of methyl-cationized uracil [(uracil) $\left.\mathrm{CH}_{3}\right]^{+}(\mathrm{m} / z$ 127, vide infra $)$. In summary, the unimolecular reactivity of the $[\mathrm{RHg}(\mathrm{NB})]^{+}$complexes is apparently simple, but specific because of the nucleobase alkylation process. Whereas, like for alkali metals, [75-77] elimination of intact nucleobase from the initial complex is present, we do not observe any cleavage of the pyrimidic ring like those reported for $\mathrm{Cu}^{2+}, \mathrm{Pb}^{2+}$ or $\mathrm{Sn}^{2+}$ ions $[20,22,25,29]$. 


\section{b) Study of the $[\mathrm{RHg}(\mathrm{NB})]^{+}$complexes}

Computational study. In order to rationalize and complement our experimental findings, we have performed DFT calculations in order to obtain the geometry and the relative energies of the $[\mathrm{RHg}(\mathrm{NB})]^{+}$and $[(\mathrm{NB}) \mathrm{R}]^{+}$complexes. We have carried out an exhaustive investigation not only on the products arising from the direct attachment of the $\left[\mathrm{CH}_{3} \mathrm{Hg}\right]^{+}$ or the $[\mathrm{n}-\mathrm{BuHg}]^{+}$cation to the two carbonyl groups, but to all other possible conformers that can be obtained from these initial species. In what follows, we have adopted the following nomenclature $\mathbf{U N H g}$ and $\mathbf{U N H g}$ ' to name the uracil to which the $\left[\mathrm{CH}_{3} \mathrm{Hg}\right]^{+}$or $[\mathrm{n}-\mathrm{BuHg}]^{+}$cation is attached, $\mathrm{N}$ being the position of the ring $(\mathrm{N}=1-6)$ in which the attachment takes place. Hence, for instance $\mathbf{U} 2 \mathbf{H g}$ will indicate that $\left[\mathrm{CH}_{3} \mathrm{Hg}\right]^{+}$is attached to the $\mathrm{O} 2$ oxygen atom (the one attached to $\mathrm{C} 2$ ) of uracil, whereas $\mathbf{U} \mathbf{4 H g}$ ' will indicate that $[\mathrm{n}-\mathrm{BuHg}]^{+}$is attached to the $\mathrm{O} 4$ oxygen atom (the one attached to $\mathrm{C} 4$ ) of uracil. The need of secondary labels to account for the different orientations of the groups is summarized in the scheme contained in Figure 2. Since the C-O-X arrangement is bent, two conformers, a and $\mathbf{b}$, can be envisaged when the cation is attached to $\mathrm{O} 4$ and another two, $\mathbf{c}$ and $\mathbf{d}$, when attached to $\mathrm{O} 2$ (see Figure 2). The nomenclature for the enol forms follows the same criteria but the name is preceded by "E". However, in the enol forms we have to indicate not only the relative position of the $\mathrm{Hg}$ or $\mathrm{Hg}$ ' group, but also the relative position of the $\mathrm{H}$ atom of the $\mathrm{OH}$ group of the enol function. For instance E-U4Hgac will designate that the $\left[\mathrm{CH}_{3} \mathrm{Hg}\right]^{+}$fragment is oriented to the right of the ring (a) and the $\mathrm{H}$ of the $\mathrm{OH}$ group in cis position (c) to it (see Figure 2). Hence, the alternative orientations of both $\left[\mathrm{CH}_{3} \mathrm{Hg}\right]^{+}$and the hydrogen of the enol group would lead to the E-U4Hgbd conformer. 


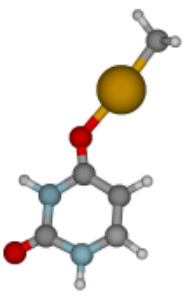

U4Hga

0

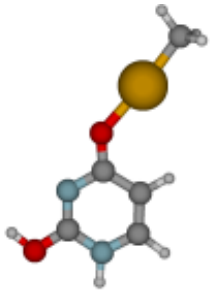

E-U4Hgac

33.6

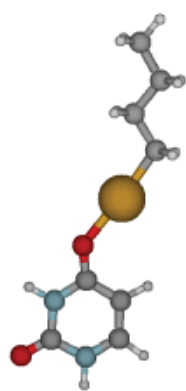

U4Hg'a

0.2

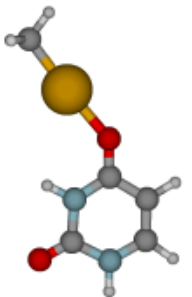

U4Hgb

5.6

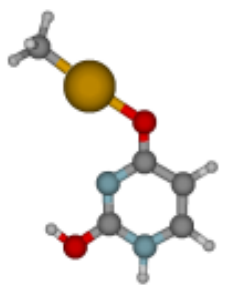

E-U4Hgbc

12.1

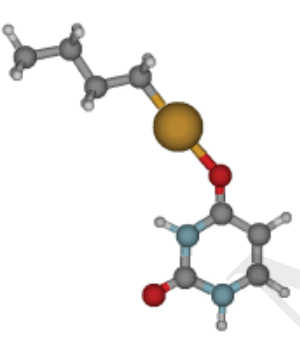

U4Hg'b

0

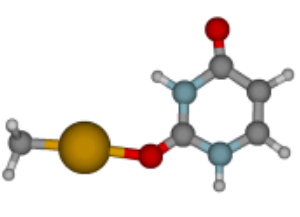

U2Hgc

19.9

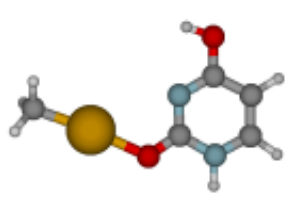

E-U2Hgbc

1.3

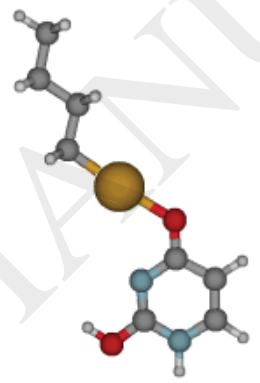

E-U4Hg'bc

17.5

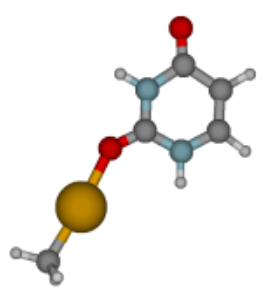

U2Hgd

21.7

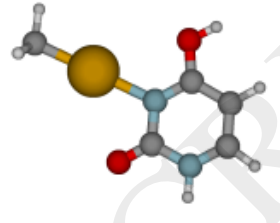

E-U3Hga

11.2

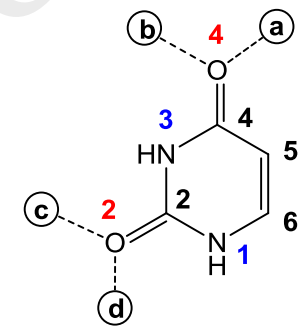

(d)

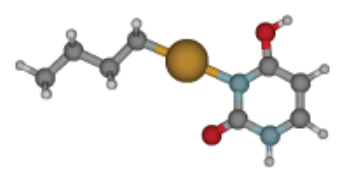

E-U2Hg'bc

5.4

16.6

Figure 2 : Structure and B3LYP/6-311++G(3df,2p)+DEF2-QZVPD+ZPE relative free energies $\left(\mathrm{kJ} \cdot \mathrm{mol}^{-1}\right)$ of the lowest-energy structures obtained for the $\left[\mathrm{CH}_{3} \mathrm{Hg}(\text { uracil })\right]^{+}$and $\left[\mathrm{n}-\mathrm{BuHg}(\text { uracil) }]^{+}\right.$ complexes. See details in the text for the nomenclature adopted.

For the sake of conciseness, we are not going to discuss in detail the structures of the complexes investigated. A total of 43 complexes between uracil and $\left[\mathrm{CH}_{3} \mathrm{Hg}\right]^{+}$cations, including enol and dienol forms have been explored. The same number of complexes were 
analyzed for the interactions with $[\mathrm{n}-\mathrm{BuHg}]^{+}$. Their structures and relative energies are shown in Figures S1 and S2 and Table S1, respectively, of the Supporting Information. The same number of [uracil-Me $]^{+}$and $[\text {uracil-nBu}]^{+}$cations were investigated and their structures and relative stabilities are summarized in Figures S3, S4 and Table S2 of the Supporting Information.

IRMPD spectrum of the $\left[\mathrm{CH}_{3} \mathrm{Hg} \text { (uracil) }\right]^{+}$complex. We have deduced from the theoretical study that two forms, U4Hga and E-U2Hgbc, are practically degenerate. Consequently, in order to determine if these particular forms or alternate structures were actually generated in the gas phase, we recorded the IRMPD spectrum of the $\left[\mathrm{CH}_{3} \mathrm{Hg}(\text { uracil })\right]^{+}$complex, which is shown in Figure 3a. The fragment ion observed during IRMPD activation corresponds to methylated uracil through the elimination of $\mathrm{Hg}^{\circ}$.

The IRMPD spectrum recorded for $\left[\mathrm{CH}_{3} \mathrm{Hg} \text { (uracil) }\right]^{+}$exhibits 6 intense bands at 1175 , $1210,1335,1415,1467$ and $1600 \mathrm{~cm}^{-1}$, and two other interesting features at 1545 and 1805 $\mathrm{cm}^{-1}$. The IRMPD bands can be assigned by comparing the experimental spectrum with the DFT-computed vibrational spectra of low energy-lying structures. It is worth reminding that the computed IR intensities assume single photon absorption, which differs from the IRMPD process [78, 79]. Therefore, as far as intensities are concerned, computed IR spectra may not correspond well with the experimental abundances. As can be seen in Figure 3, almost all the IRMPD bands can be assigned by considering the IR active modes of the enolic form E-U2Hgbc, which are summarized in Table S3 of the Supporting Information. The IRMPD band detected at $1175 \mathrm{~cm}^{-1}$ may be interpreted as the $\mathrm{OH}$ bending mode of the enolic group. The intense feature detected at $1210 \mathrm{~cm}^{-1}$ can be assigned to different combinations of $\mathrm{C}-\mathrm{H}$ and $\mathrm{N}-\mathrm{H}$ bending modes of uracil and the $\mathrm{CH}_{3}$ umbrella bending mode of the $\mathrm{CH}_{3} \mathrm{Hg}$ moiety. The signals observed at 1335 and $1415 \mathrm{~cm}^{-1}$ 
may be also ascribed to C-H and N-H bending modes of uracil. The band detected at 1467 $\mathrm{cm}^{-1}$ can be attributed to the $\mathrm{C} 4 \mathrm{O} 4$ stretching mode.

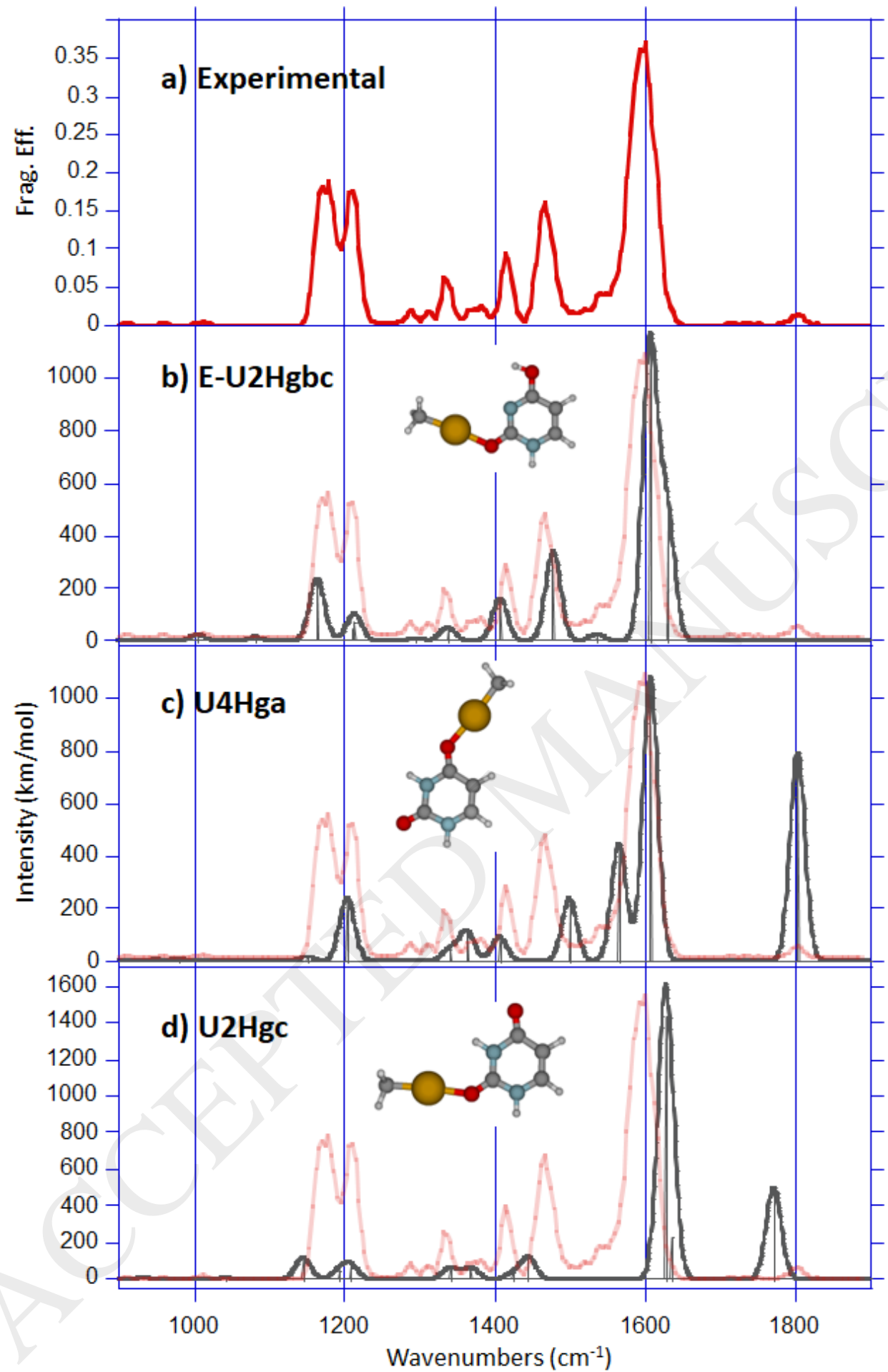

Figure 3: (a) IRMPD spectrum obtained for the $\left[\mathrm{CH}_{3}\right) \mathrm{Hg}$ (uracil) $]^{+}$complex compared to DFT-computed IR absorption spectra (b-d) of some relevant structures. The experimental IRMPD spectrum is overlayed in red. 
This stretching mode is logically significantly red-shifted with respect to the diketo form of uracil, due to the presence of the enolic group. The very intense feature detected at 1600 $\mathrm{cm}^{-1}$ corresponds to the C5C6 bond stretch. Finally the shoulder observed at $1545 \mathrm{~cm}^{-1}$ on the red side of this intense signal can be attributed to the C4C5 bond stretch. The last weak but informative signal observed at $1805 \mathrm{~cm}^{-1}$ cannot be interpreted by the computed spectrum of E-U2Hgbc, and therefore indicates that the $\mathrm{m} / \mathrm{z}, 329$ ion corresponds to the mixture of at least two different forms. The experimental band observed is very probably the stretching of an unperturbed uracil carbonyl group as already observed for other systems $[29,80]$. The very good agreement between the $\mathrm{C} 2 \mathrm{O} 2$ stretch of the global minimum U4Hga computed at $1803 \mathrm{~cm}^{-1}$ (Table S3) and the experimental signal, suggests that this form is likely generated. A good agreement is also observed for other experimental bands $\left(1210,1415,1600 \mathrm{~cm}^{-1}\right)$ and supports this assumption. The rotamer U4Hgb may also be generated as its computed spectrum is very similar to that of U4Hga (Figure S5). The agreement is less good with the keto forms U2Hgc and U2Hgd although they cannot be rigorously discarded. The experimental IRMPD spectra of the three other complexes have been also recorded (Figure S6), but will not be discussed in detail. They appeared to be very similar to the spectrum reported in Figure 3a, suggesting that similar structures should be generated in the gas phase.

\section{b) Study of the methylation product of uracil}

As the most remarkable process observed upon CID conditions is the alkylation of the nucleobases, we tried a) to characterize in detail the structure of the ion arising from the methylation of uracil, and b) to propose some mechanisms accounting for its formation. We first performed a series of MS/MS experiments in order to compare the MS/MS spectrum of the $\left[(\text { uracil }) \mathrm{CH}_{3}\right]^{+}$ion $(\mathrm{m} / \mathrm{z}, 127)$ to that of the protonated form of four different 
methyl uracils (1-Me-uracil, 3-Me-uracil, thymine, 6-Me-uracil). The CID spectra recorded at the same collision energy are gathered in Figure 4.
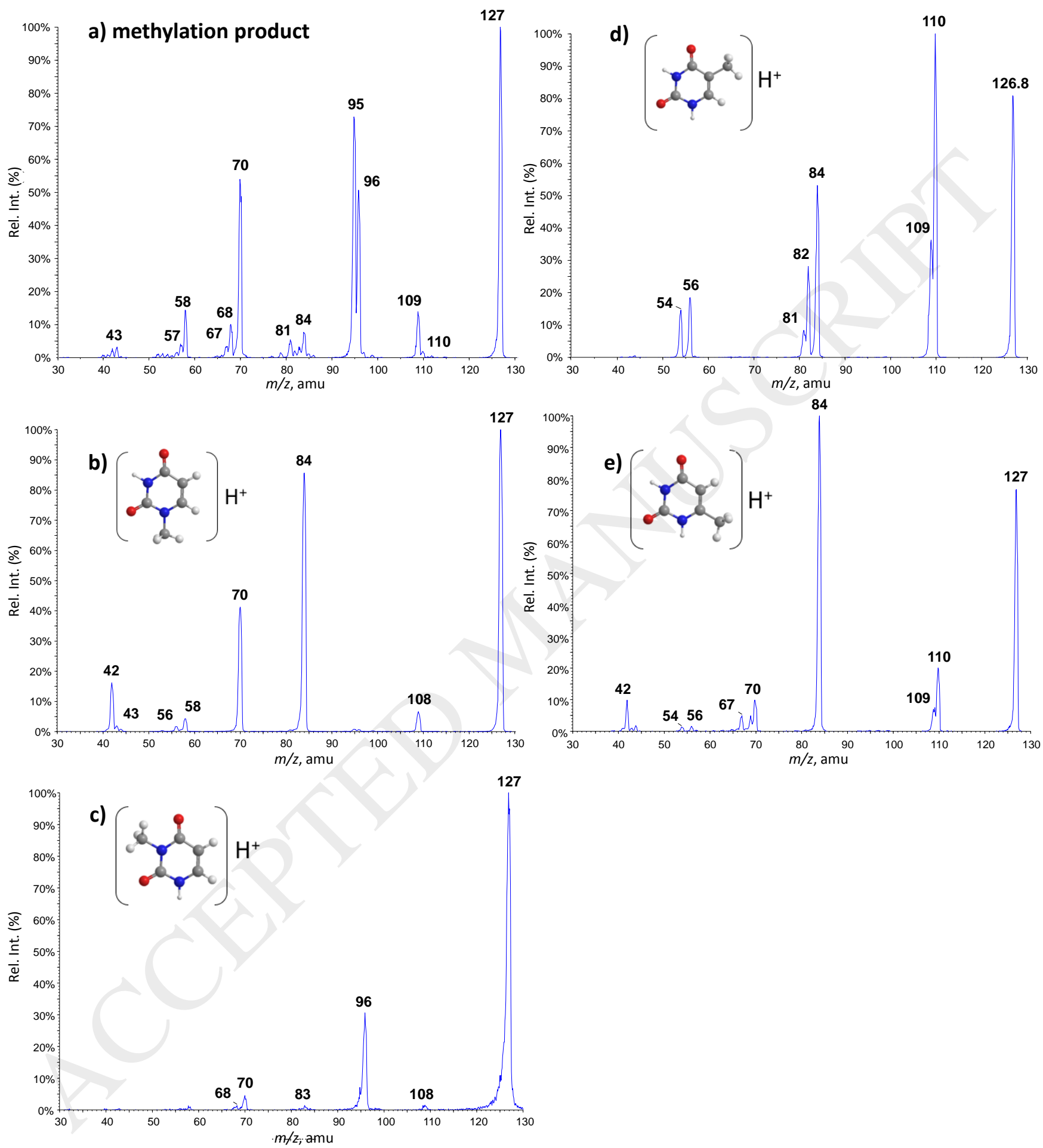

Figure 4: comparison of the CID spectrum of the ion arising from methylation of uracil with those of protonated methyl-uracil isomers. Each spectrum recorded at a collision energy of $25 \mathrm{eV}$ (Lab.). 
When examining this Figure, one can immediately see that each spectrum is associated with a specific set of fragment ions. A detailed description of these spectra is beyond the scope of the present paper, but the MS/MS spectrum of the methylation product is the only one exhibiting very intense fragment ions both at $\mathrm{m} / \mathrm{z} 70,96$ and 95 , the latter one being clearly specific (Figure 4a). Consequently, these experiments demonstrate that the ion generated by methyl transfer from $\left[\mathrm{CH}_{3} \mathrm{Hg}\right]^{+}$to uracil, does not correspond to a protonated methyl-uracil isomer.

In order to go further, we also recorded the IRMPD spectrum of the $\left[(\text { uracil }) \mathrm{CH}_{3}\right]^{+}$ion by first performing the fragmentation of the $\left[\mathrm{CH}_{3} \mathrm{Hg} \text { (uracil) }\right]^{+}$complex within the ion trap, then selecting the $\mathrm{m} / \mathrm{z} 127$ ion, and finally performing the IRMPD activation during the $\mathrm{MS}^{3}$ step. The resulting IRMPD spectrum is reported in Figure 5a. First, one can see that this spectrum strongly differs from those recorded for the protonated forms of the four methyl-uracil isomers, and reported recently [81]. Therefore, this confirms the information deduced from CID experiments. Comparison with the harmonic vibrational spectra computed for different structures shows that the best agreement is obtained, like for the $\left[\mathrm{CH}_{3} \mathrm{Hg} \text { (uracil) }\right]^{+}$complex, with the most stable form, namely U4a (Figure $5 b$ ). The experimental bands detected at $1210,1309,1563,1595$ and $1802 \mathrm{~cm}^{-1}$ are notably very well reproduced and can be interpreted as follows (see also Table S4 of the supporting information). The signal at $1210 \mathrm{~cm}^{-1}$ can correspond to a combination of $\mathrm{C}-\mathrm{H}$ and $\mathrm{N}-\mathrm{H}$ bending modes while the bands detected at $1309 \mathrm{~cm}^{-1}$ can be ascribed to the $\mathrm{N} 3 \mathrm{H}$ bending mode. The three bands observed at 1563,1595 and $1802 \mathrm{~cm}^{-1}$ can be attributed to the C4C5, C5C6 and C2O2 stretches, respectively. The experimental signal detected at 1483 $\mathrm{cm}^{-1}$ might correspond to the band computed at $1515 \mathrm{~cm}^{-1}$ and attributed to the $\mathrm{N} 3 \mathrm{C} 4$ stretch. The agreement with the DFT-computed spectrum of the rotamer U4b slightly less stable $(+7.2 \mathrm{~kJ} / \mathrm{mol})$ (Figure $5 \mathrm{c})$ is also very good, while the spectrum recorded for $\mathbf{U} 2 \mathrm{c}$ 
does not reproduce the experiment very properly. These data therefore suggest that alkylation of the uracil moiety would preferentially occur onto the $\mathrm{C} 4=\mathrm{O} 4$ carbonyl group.

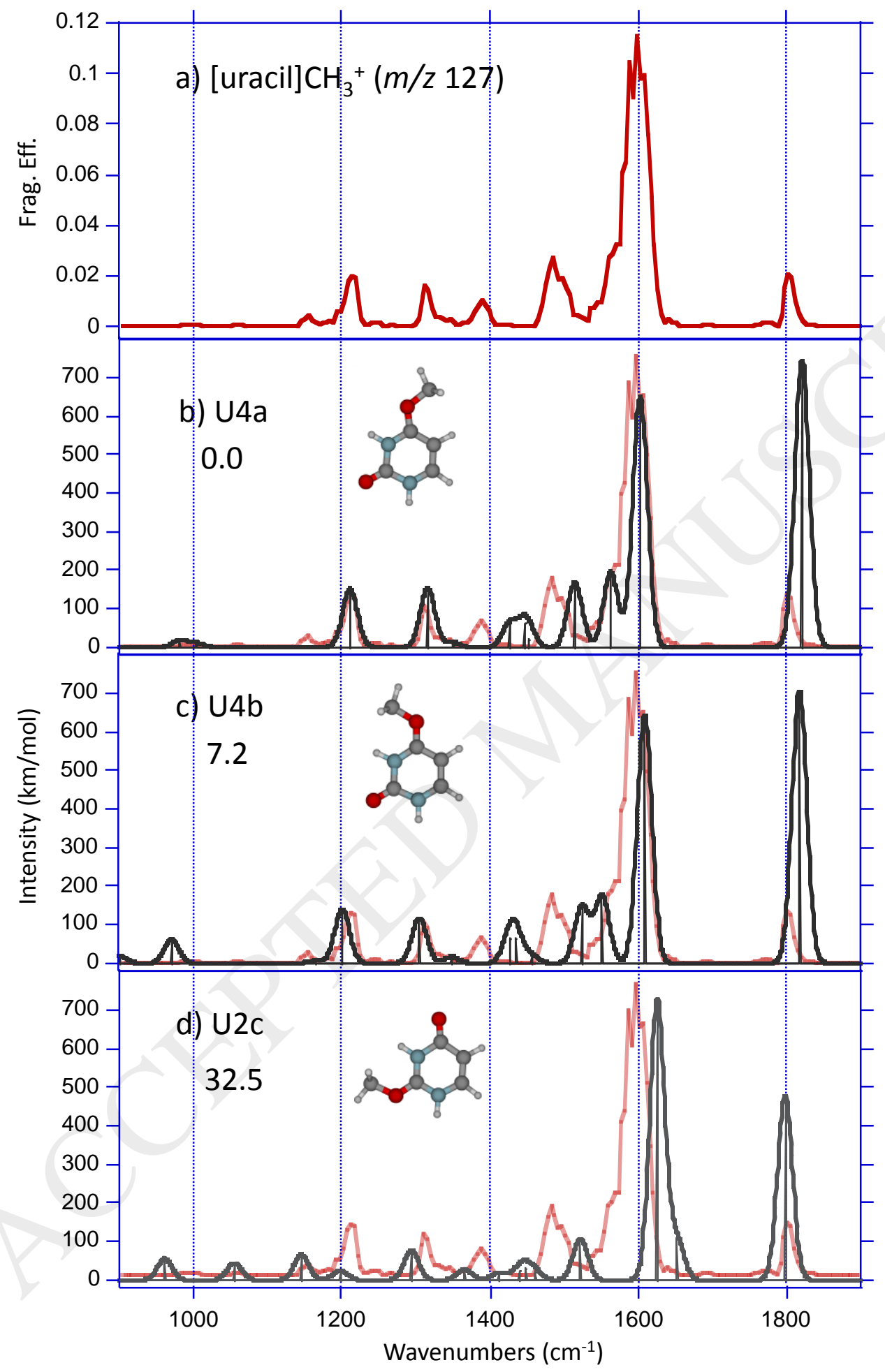

Figure 5: (a) IRMPD spectrum obtained for the [(uracil) $\left.\mathrm{CH}_{3}\right]^{+}$ion $(\mathrm{m} / \mathrm{z}$ 127) compared to DFT-computed IR absorption spectra (b-d) of some relevant structures. The experimental IRMPD spectrum is overlayed in red. 
Uracil alkylation mechanism. As mentioned above, the initial step of the alkylation process of uracil upon its interaction with $[\mathrm{RHg}]^{+}$cations should start with the association of the alkylmercury cation to the two available basic sites, either $\mathrm{C} 4 \mathrm{O}$ or $\mathrm{C} 2 \mathrm{O}$. The energy profiles associated with these two processes are shown in Figures 6a and 6b, respectively. A comparison between the two figures shows that the association of the $\left[\mathrm{CH}_{3} \mathrm{Hg}\right]^{+}$cation to the $\mathrm{C} 4=\mathrm{O}$ carbonyl group is more favorable from the energetic viewpoint than the association to the $\mathrm{C} 2=\mathrm{O}$ one, even though the energy difference is not significantly large. The second important point is that the mechanisms are very similar in both cases. We have considered as the first step the possibility of producing the corresponding enol form, which in these systems usually plays an important role. As a matter of fact, it is found that the enol form in the second case, E-U2Hgbc is more stable than the keto one, U2Hgc (Figure $6 b$ ). When the attachment of $\left[\mathrm{CH}_{3} \mathrm{Hg}\right]^{+}$cation takes place at the $\mathrm{C} 4=\mathrm{O}$ group (Figure $6 \mathrm{a}$ ), both forms, U4Hgb and E-U4Hgbc are nearly degenerate, the keto one being slightly more stable than the enol form. The enol forms, again in both cases, may evolve following two alternative pathways. The formation of the enol form leaves a very basic imino nitrogen accessible to $\left[\mathrm{CH}_{3} \mathrm{Hg}\right]^{+}$attachment, which in both cases takes place after surpassing a rather low activation barrier, yielding the corresponding E-U3Hgb and E-U3Hgc nitrogen attached species, respectively. However, both nitrogen attached species are less stable than the oxygen attached ones, so due to the low activation barriers, one should expect that EU3Hgb and E-U3Hgc forms will revert to E-U2Hgbc and E-U4Hgbc, respectively. The second pathway connects the oxygen attached enol form with the products through the transition states TSU4_EP and TSU2_EP, respectively. In both cases the mechanism is similar because both transition states show the formation of a three-membered ring in which the methyl group of the $\mathrm{CH}_{3} \mathrm{Hg}$ subunit is bonded to both the $\mathrm{Hg}$ atom and the $\mathrm{O}$ atom of the free carbonyl group. Indeed, as illustrated in Figure 7, the molecular graphs of 
both transition states, the $\mathrm{O}-\mathrm{Hg}$ bond becomes rather weak, whereas a new $\mathrm{O}-\mathrm{CH}_{3}$ starts to be formed.

a)

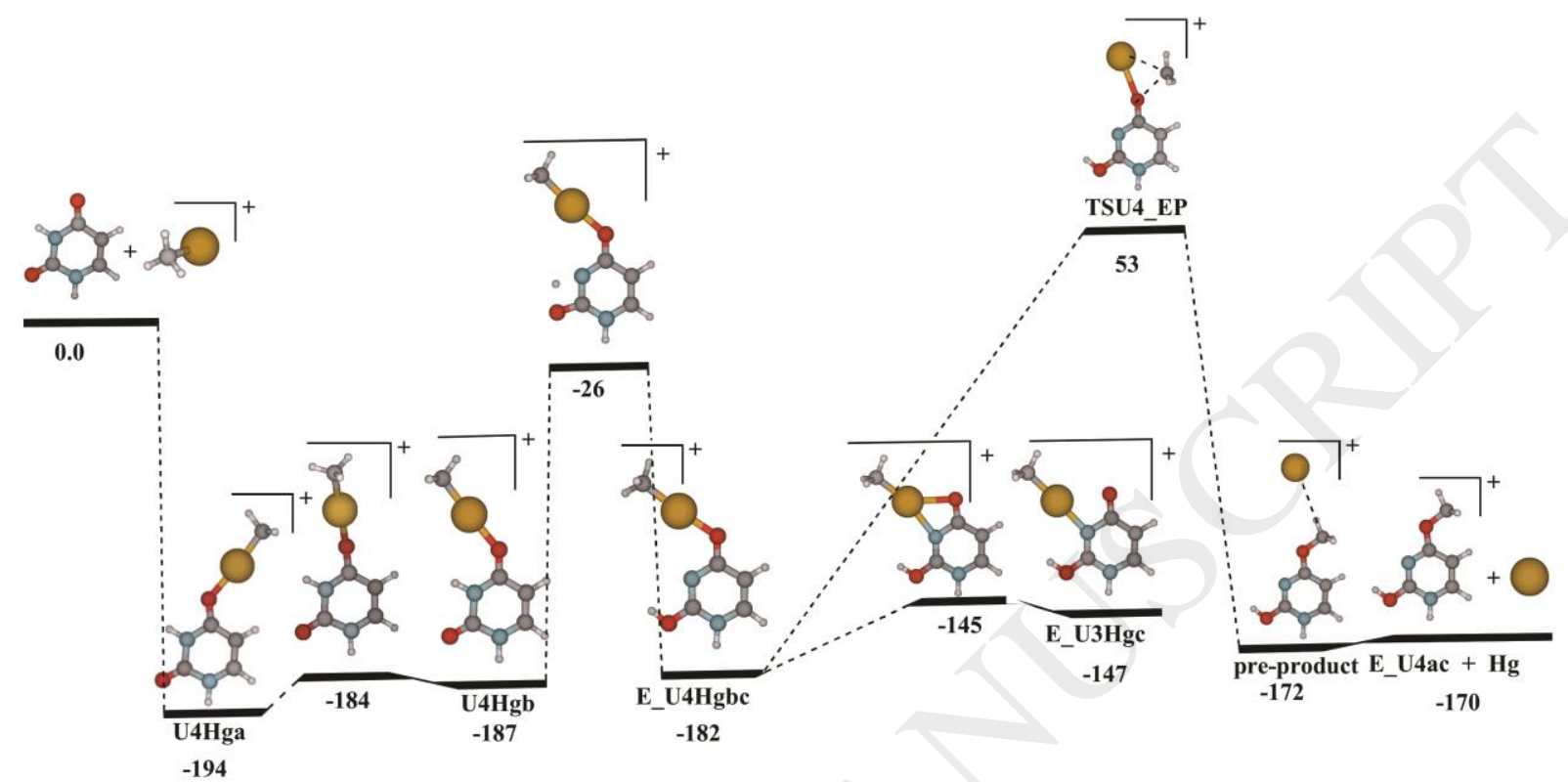

b)

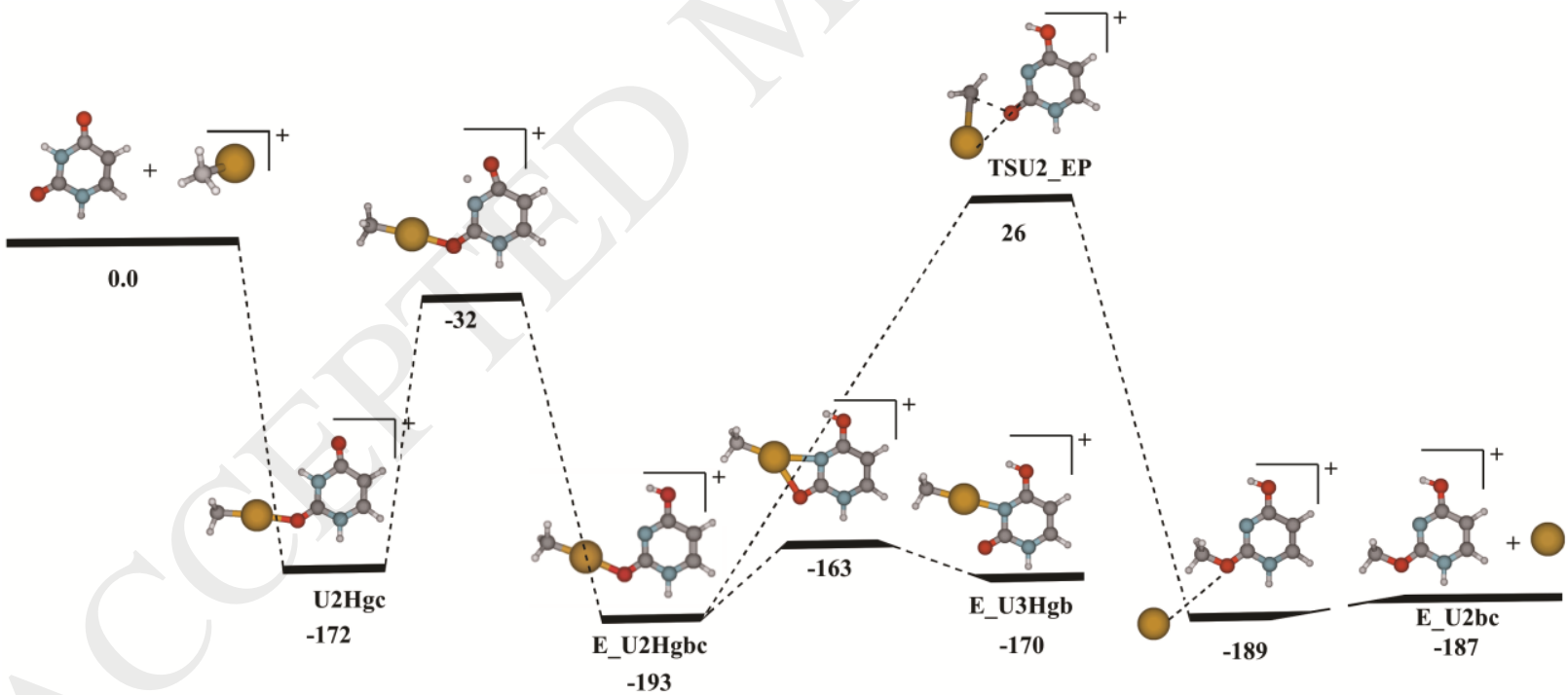

Figure 6. Energy profile corresponding to the association of $\left[\mathrm{CH}_{3} \mathrm{Hg}\right]^{+}$to a) the $\mathrm{C} 4=\mathrm{O}$ carbonyl group and $\mathbf{b}$ ) the $\mathrm{C} 2=\mathrm{O}$ carbonyl group of uracil. All values in $\mathrm{kJ} \cdot \mathrm{mol}^{-1}$. 

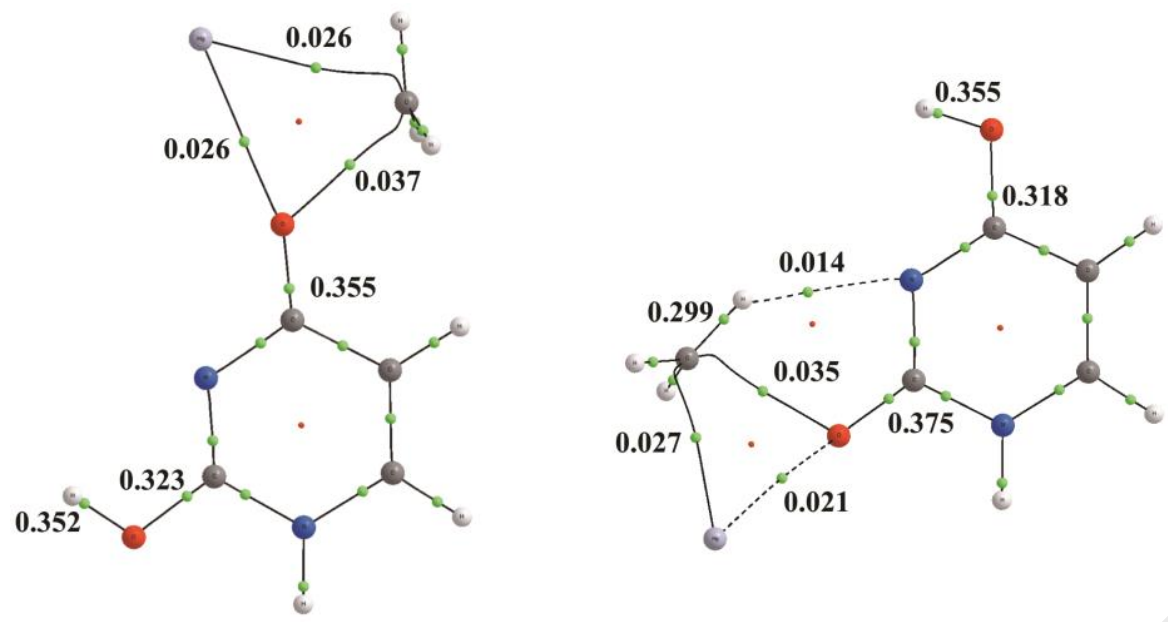

Figure 7. Molecular graphs of the TSU4_EP and TSU2_EP transition states. Green and red dots designate bond and ring critical points, respectively. The electron densities are in a.u.

Both transitions states evolve to a local minimum in which the methyl group becomes covalently bound to the oxygen atom of the free carbonyl group, whereas the neutral $\mathrm{Hg}^{\circ}$ atom interacts weakly with the rest of the molecule. Again in both cases, this intermediate dissociates, with a very small amount of energy, into the corresponding Methyl-uracil cation and $\mathrm{Hg}^{\circ}$, which is the dominant process observed experimentally. In the mechanisms showed above, the products are the enolic forms of the methyl-uracil cation, but the tautomerization to yield the corresponding keto forms, the ones observed experimentally, would be just the subsequent step not shown in the figure.

It is important mentioning that the mechanism described in Figure 6 could compete with a SN2 mechanism, like the one described for the methylation of ammonia by $\mathrm{MCH}_{3}{ }^{+}$ions $(\mathrm{M}=\mathrm{Zn}, \mathrm{Cd}, \mathrm{Hg})$ [8]. Transposed to our system, this mechanism would start from a complex between uracil and $\left[\mathrm{CH}_{3} \mathrm{Hg}\right]^{+}$where the nucleobase binds the cation through the methyl group instead of $\mathrm{Hg}$. However, similarly to what was reported for the $\mathrm{CH} 3 \mathrm{Hg}^{+} / \mathrm{NH}_{3}$ system, we could not locate this complex. Nonetheless, we found two isomers of the preproduct, depending on the site of the reaction, $\mathrm{O} 2$ or $\mathrm{O} 4$ (see Figure $\mathrm{S} 7$ of the 
supporting information), that could arise from that kind of process, and which are very close in energy from E-U2Hgbc and U4Hga Concerning the enolic forms, the agreement with experiment appears to be better for E-U2Hgbc than for the SN2 preproduct (Figure S7A).

c) Protonation of uracil from the $\left[\mathrm{n}-\mathrm{BuHg}(\text { uracil) }]^{+}\right.$complex

Since the formation of protonated uracil is only observed for the reactions with [n-BuHg$]^{+}$ cations, we have explored the possible mechanisms only for this cation. The fact that this reaction is not observed for reactions with $\left[\mathrm{CH}_{3} \mathrm{Hg}\right]^{+}$cations can be taken as an indication that the length and the flexibility of the alkyl chain is critical for this particular processes, and indeed this is corroborated by the mechanism we could design based on our DFT calculations. As in the case of the alkylation mechanisms, the two carbonyl groups are the

\section{a)}

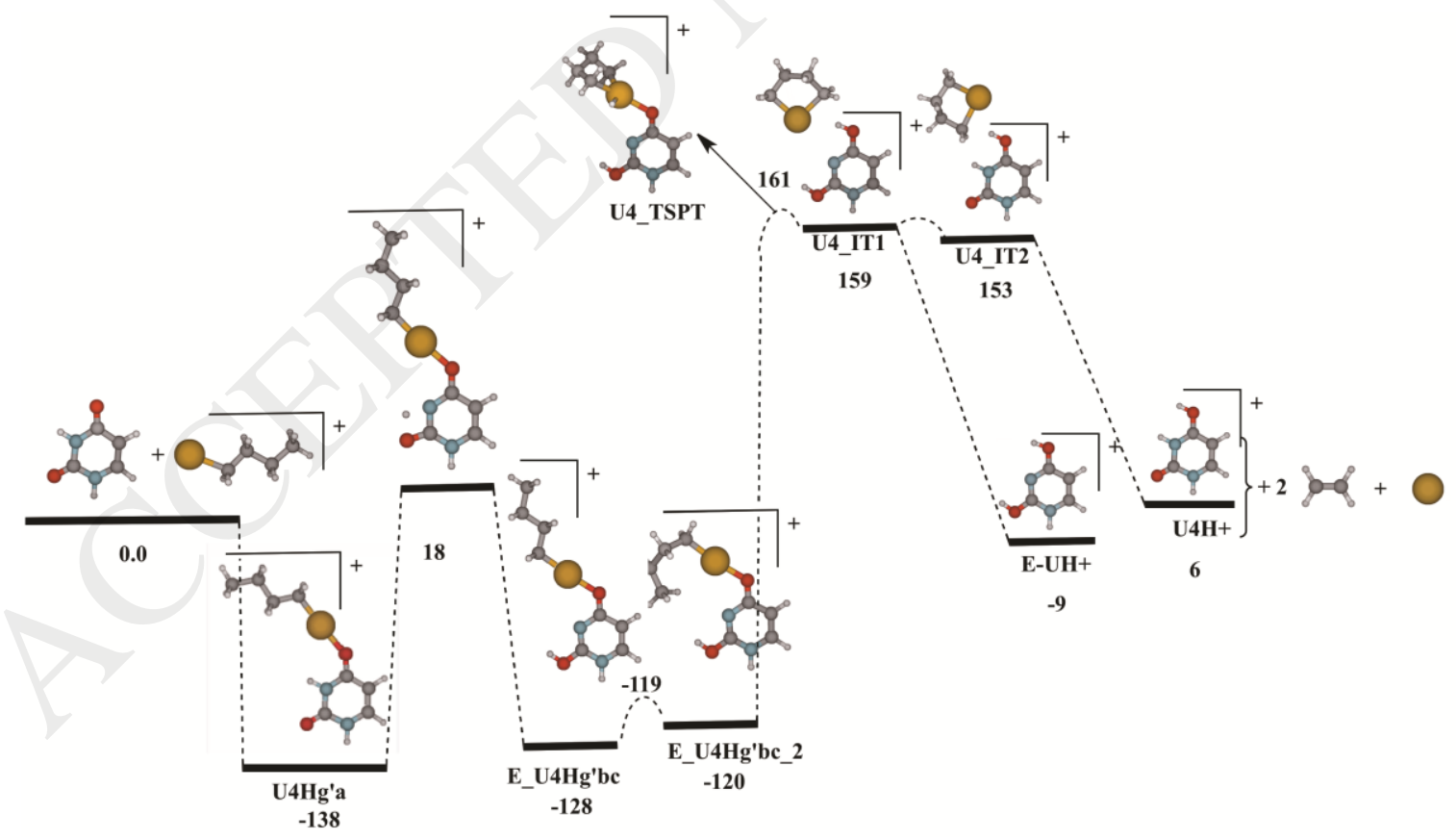

b) 


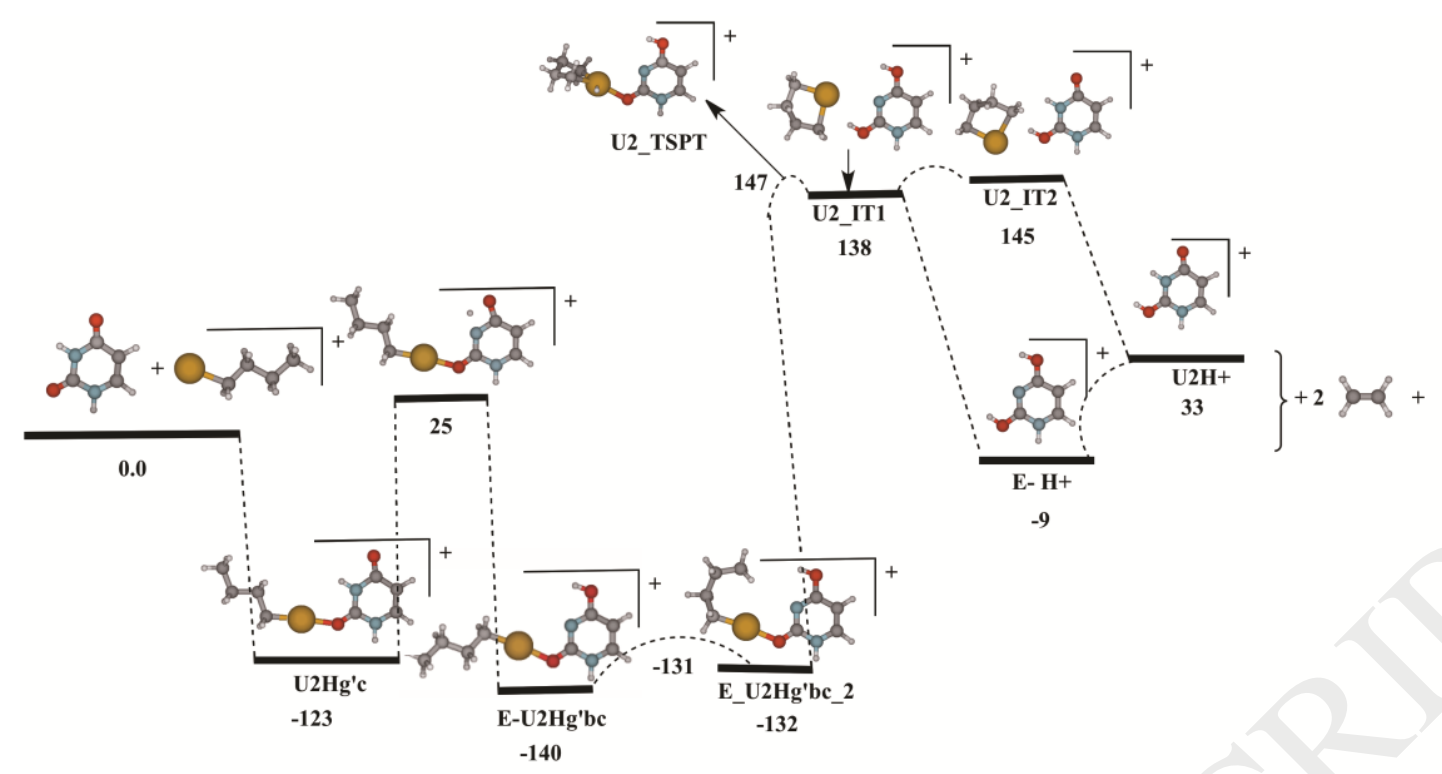

Figure 8. Energy profile associated with the formation of protonated uracil from the attachment of $[\mathrm{n}-\mathrm{BuHg}]^{+}$cation to its a) $\mathrm{C} 4=\mathrm{O}$ and b) $\mathrm{C} 2=\mathrm{O}$ carbonyl group. All values in $\mathrm{kJ} \cdot \mathrm{mol}^{-1}$.

only available sites for the direct attachment of the $[\mathrm{n}-\mathrm{BuHg}]^{+}$. The energy profile associated with the process of producing protonated uracil when the cation attachment takes place at the $\mathrm{C} 4=\mathrm{O}$ carbonyl group is shown in Figure 8a, whereas Figure $8 \mathrm{~b}$ shows the equivalent mechanism when the attachment occurs at the $\mathrm{C} 2=\mathrm{O}$ group.

As it was found for the case of the reactions of $\left[\mathrm{CH}_{3} \mathrm{Hg}\right]^{+}$with uracil, the association of $[\mathrm{n}-$ $\mathrm{BuHg}^{+}$to $\mathrm{C} 4=\mathrm{O}$ to yield $\mathbf{U} \mathbf{4 H g}$ 'a is energetically more favorable than the association to $\mathrm{C} 2=\mathrm{O}$ to yield U2Hg'c. However, in both cases, differently to what was found for the $\left[\mathrm{CH}_{3} \mathrm{Hg}\right]^{+}$reactions, the activation barriers associated to the formation of the corresponding enols are slightly higher in energy than the entrance channel. Once the enols E-U4Hg'bc and E-U2Hg'bc have been formed, the subsequent step to favor a proton transfer from the butyl chain towards the uracil cycle, requires a folding of the alkyl chain, which implies a rather low activation barrier yielding two new local minima, namely EU4Hg'bc_2 and E-U2Hg'bc_2, respectively. The proton transfer from the alkyl chain towards the uracil moiety goes through a transition state (U4_TSPT and U2_TSPT) in 
which a first proton transfer goes from the alkyl chain to the $\mathrm{Hg}$ atom, with the concomitant cyclization of the $\left(\mathrm{CH}_{2}\right)_{4} \mathrm{HgH}$ moiety. In these transitions states, as revealed by the corresponding molecular graphs (See Figure 9), the $\mathrm{Hg}$ atom appears tertracoordinated and attached to the $\mathrm{C}=\mathrm{O}$ group of the uracil moiety. However, as soon as the proton attached to the $\mathrm{Hg}$ atom is transferred to the oxygen atom, to yield the intermediates U4_IT1 and U2_IT1 only a very weak interaction between the $\left(\mathrm{CH}_{2}\right)_{4} \mathrm{Hg}$ five-membered ring and the uracil moiety remains.

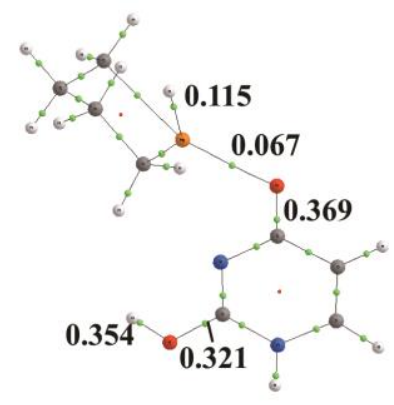

U4_TSPT

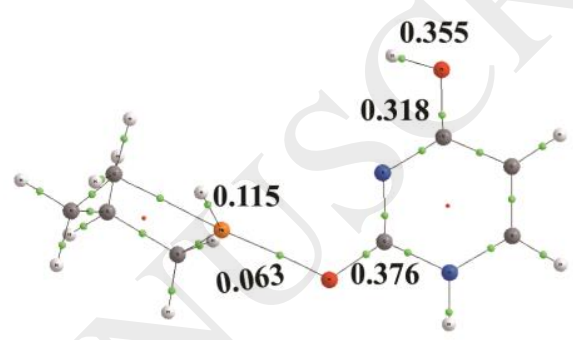

U2_TSPT

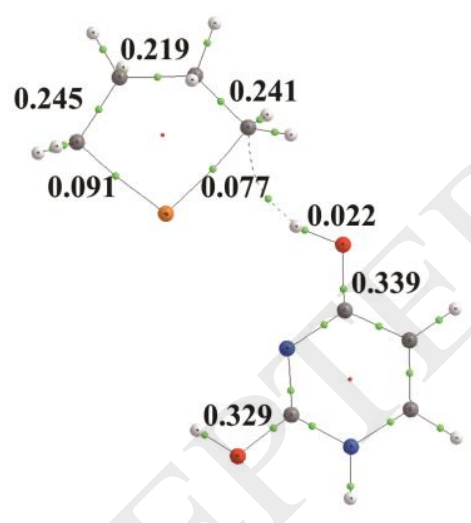

U4_IT1

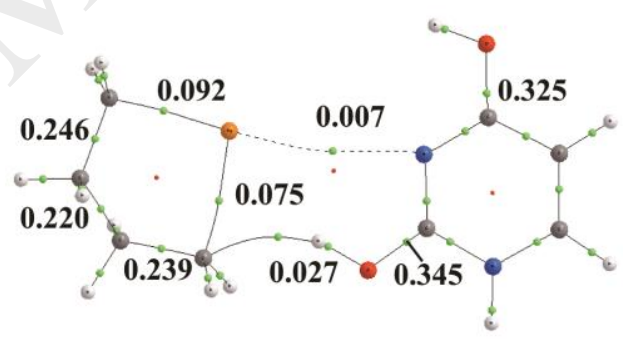

U2_IT1

Figure 9. Molecular graphs of the U4_TSPT and U2_TSPT transition states, and the intermediates, U4_IT1 and U2_IT1, produced when the proton transfer from the $\left(\mathrm{CH}_{2}\right)_{4} \mathrm{HgH}$ subunit to the uracil moiety is completed. Green and red dots designate bond and ring critical points, respectively. The electron densities are in a.u.

In principle one would expect that the formation of the protonated species should be accompanied by the loss of a $\left(\mathrm{CH}_{2}\right)_{4} \mathrm{Hg}$ five-membered ring from the aforementioned 
intermediates. However, as soon as this $\left(\mathrm{CH}_{2}\right)_{4} \mathrm{Hg}$ subunit separates from the protonated uracil molecule, it starts dissociating into two molecules of ethylene and one atom of $\mathrm{Hg}^{\circ}$, so the proton transfer leads to the formation of a dienol-uracil cation accompanied by the loss of the aforementioned fragments. As shown in both figures, this exit channels is slightly exothermic with respect to the entrance channel by $9 \mathrm{~kJ}^{\mathrm{mol}}{ }^{-1}$. It is worth noting that in a previous IRMPD study of protonated uracil, [82] it was also found the di-enol to be the dominant form, whereas the keto form protonated at $\mathrm{O} 4$ was much less abundant. A concomitant proton transfer to the imino nitrogen to form two alternative intermediates, U4_IT2 and U2_IT2 cannot be discarded because their stability is only slightly lower (see Figures 9a) or slightly higher (see Figure 9b) than those found for the transfer to the carbonyl group. The difference is that in both cases not a di-enol but an enol structure is formed, the two processes being slightly endothermic (by 6 and $33 \mathrm{~kJ} \cdot \mathrm{mol}^{-1}$, respectively) rather than exothermic with respect to the entrance channel. It should be remembered however that both mechanisms, as mentioned above, imply activation barriers clearly higher in energy than the entrance channel, and therefore the formation of protonated uracil in any of its forms, should be clearly a minority. The fact that protonated uracil is the most intense fragment ion observed experimentally with $\mathrm{n}-\mathrm{BuHgCl}$ (Figure $1 \mathrm{~b}$ ) may reflect the fact that experiments are carried out under a multiple collision regime, leading to the increase of the internal energy of the precursor ions, which would allow these high activation barriers to be overpassed. Furthermore, we already demonstrated by using statistical kinetic theories that the products which are thermochemically favored are not necessarily kinetically favored [83].

It is worth mentioning that a mechanism in which the resulting products arise from a betahydride elimination in the $\mathrm{n}$-Bu chain starting from the U4Hg'a / U4Hg'c structures cannot be ruled out (see Figure $\mathbf{S} 8$ in the Supporting Information file). The transition state 
for this process lies at $182 \mathrm{~kJ} / \mathrm{mol}$ above the entrance channel in Figure 8a, therefore higher in energy than the bottle-neck of the proposed PES.

\section{Concluding remarks.}

The gas-phase reactions between uracil or thymine and alkyl mercury cations, $[\mathrm{RHg}]^{+}(\mathrm{R}=$ $\mathrm{Me}, \mathrm{n}-\mathrm{Bu})$, form a single type of complex $[\mathrm{RHg}(\mathrm{NB})]^{+}$. Our combined experimentaltheoretical approach explains how the dominant reaction pathway from these $[\mathrm{RHg}(\mathrm{NB})]^{+}$ complexes leads to the alkylation of the nucleobase, $[\mathrm{R}(\mathrm{NB})]^{+}$, with the concomitant loss of neutral $\mathrm{Hg}$. Only when the alkyl chain is long enough, as in the case of $\mathrm{R}=\mathrm{nBu}$, there is a second reactive pathway producing the protonated nucleobase, $[(\mathrm{NB}) \mathrm{H}]^{+}$, and the loss of $\mathrm{C}_{4}, \mathrm{H}_{8}, \mathrm{Hg}$. From the electronic structure calculations we showed that this latter $\mathrm{C}_{4}, \mathrm{H}_{8}, \mathrm{Hg}$ subunit is a five-membered ring, which upon departure from the protonated nucleobase spontaneously leads to two ethylene molecules plus neutral Hg. A comparison of the IRMPD spectra with the calculated harmonic vibrational frequencies for $\left[\mathrm{CH}_{3} \mathrm{Hg}(\text { uracil })\right]^{+}$ indicates that the $\left[\mathrm{CH}_{3} \mathrm{Hg}\right]^{+}$subunit is attached to carbonyl group. The predominant conformer should be the enolic E_U2Hgbc form, with some contribution of the keto forms U4Hga or U4Hgb, which present pretty similar vibrational features.

The MS/MS spectrum of the methylation product indicates that the ion generated by methyl transfer from $\left[\mathrm{CH}_{3} \mathrm{Hg}\right]^{+}$to uracil does not correspond to a protonated methyl-uracil isomer. This point was also confirmed by comparison between the IRMPD spectrum and the theoretical spectra for the different structures, from which the keto $\mathbf{U} 4 \mathbf{a}$ form gave the best agreement. Consequently, it turns out that the methylation process occurs on a carbonyl group. If such methylation process of the carbonyl group would occur within 
DNA, it might potentially perturb the hydrogen bonding network associated with the formation of base pairs, and subsequently possibly disrupt the structure of the biopolymer.

In summary, a quite complete picture of the reactivity of uracil and thymine towards alkyl mercury cations is provided thanks to the interplay between experiment and theory, explaining the differences due to the length of the alkyl chain and the role of mercury with respect to other metals. 


\section{Acknowledgments.}

The CLIO team (J. M. Ortega, G. Perilhous, J. P. Berthet) as well as P. Maître, D. Scuderi and V. Steinmetz are warmly acknowledged for their support during the FEL experiments. This work has been also partially supported by the "Fonds pour le Rayonnement de la Recherche (FRR, Université d'Evry Val d'Essonne) and by the Projects CTQ2015-63997C2 and CTQ2016-76061-P of the Ministerio de Economía y Competitividad of Spain, FOTOCARBON-CM S2013/MIT-2841 of the Comunidad Autónoma de Madrid and by the COST Action CM1204 of the EU Framework Programme. Horizon 2020. Computational time at Centro de Computación Científica (CCC) of Universidad Autónoma de Madrid is also acknowledged.

\section{References}

[1] M. Alcamí, O. Mó, M. Yáñez, Computational Chemistry. A useful (some times mandatory) tool in mass spectrometry studies, Mass Spectrom. Rev., 20 (2001) 195245.

[2] J.M. Mercero, J.M. Matxain, X. Lopez, D.M. York, A. Largo, L.A. Eriksson, J.M. Ugalde, Theoretical methods that help understanding the structure and reactivity of gas phase ions, Int. J. Mass Spectrom., 240 (2005) 37-99.

[3] S.D. Zhou, J.L. Li, M. Schlangen, H. Schwarz, Bond Activation by Metal-Carbene Complexes in the Gas Phase, Accounts Chem. Res., 49 (2016) 494-502.

[4] H. Schwarz, Metal-mediated activation of carbon dioxide in the gas phase: Mechanistic insight derived from a combined experimental/computational approach, Coord. Chem. Rev., 334 (2017) 112-123.

[5] H. Schwarz, P. Gonzalez-Navarrete, J.L. Li, M. Schlangen, X.Y. Sun, T. Weiske, S.D. Zhou, Unexpected Mechanistic Variants in the Thermal Gas-Phase Activation of Methane, Organometallics, 36 (2017) 8-17.

[6] L. Yue, N. Wang, S. Zhou, X. Sun, M. Schlangen, H. Schwarz, The Electric Field as a "Smart" Ligand in Controlling the Thermal Activation of Methane and Molecular Hydrogen, Angew. Chem. Eng. Int. Ed. , (2018).

[7] R. Kretschmer, M. Schlangen, H. Schwarz, Efficient and Selective Gas-Phase Monomethylation versus N-H Bond Activation of Ammonia by "Bare" $\mathrm{Zn}(\mathrm{CH} 3)(+)$ : Atomic Zinc as a Leaving Group in an S(N)2 Reaction, Angew. Chem. Int. Ed., 50 (2011) 5387-5391. 
[8] R. Kretschmer, M. Schlangen, M. Kaupp, H. Schwarz, Neutral Metal Atoms Acting as a Leaving Group in Gas-Phase $\mathrm{S}(\mathrm{N}) 2$ Reactions: $\mathrm{M}(\mathrm{CH} 3)(+)+\mathrm{NH} 3-\mathrm{CH} 3 \mathrm{NH} 3++\mathrm{M}(\mathrm{M}=$ $\mathrm{Zn}, \mathrm{Cd}, \mathrm{Hg}$ ), Organometallics, 31 (2012) 3816-3824.

[9] A. Luna, B. Amekraz, J. Tortajada, J.P. Morizur, M. Alcamí, O. Mó, M. Yáñez, Modeling the Interactions between Peptide Functions and $\mathrm{Cu}(\mathrm{I})$ : Formamide- $\mathrm{Cu}^{+}$ Reactions in the Gas Phase, J. Am. Chem. Soc., 120 (1998) 5411-5426.

[10] A. Luna, M. Alcamí, O. Mó, M. Yáñez, J. Tortajada, A theoretical study of the interaction between $\mathrm{Ni}^{+}$and small oxygen and nitrogen containing bases, Int. J. Mass Spectrom., 217 (2002) 119-129.

[11] M. Alcamí, A. Luna, O. Mó, M. Yáñez, J. Tortajada, B. Amekraz, Unimolecular reactivity of strong metal-cation complexes in the gas phase: Ethylenediamine-Cu+, Chem. Eur. J, 10 (2004) 2927-2934.

[12] I. Corral, O. Mó, M. Yáñez, J.Y. Salpin, J. Tortajada, D. Moran, L. Radom, An experimental and theoretical investigation of gas-phase reactions of $\mathrm{Ca} 2+$ with glycine, Chem. Eur. J, 12 (2006) 6787-6796.

[13] O. Mó, M. Yáñez., J.Y. Salpin, J. Tortajada, Thermochemistry, Bonding and Reactivity of $\mathrm{Ni}+$ and $\mathrm{Ni2}+$ in the gas phase, Mass Spectrom. Rev., 26 (2007) 474-516

[14] A. Eizaguirre, M. Yáñez, J. Tortajada, J.-Y. Salpin, $\mathrm{Sr}^{2+}$-neutral molecules interactions. An Assessment of Theoretical Procedure, Chem. Phys. Lett., 464 (2008) 240-244.

[15] C. Trujillo, O. Mó, M. Yáñez, J. Tortajada, J.-Y. Salpin, Selenourea-Ca2+ Reactions in Gas Phase. Similarities and dissimilarities with urea and thiourea. , J. Phys. Chem. B, 112 (2008) 5479-5486.

[16] A.M. Lamsabhi, M. Yáñez, J.Y. Salpin, J. Tortajada, Gas-phase chemistry of organocopper compounds., in: Z. Rappoport, I. Marek (Eds.) The Chemistry of organocopper compounds, J.Wiley \&Sons, London, 2009.

[17] M. Hurtado, M. Monte, A.M. Lamsabhi, M. Yáñez, O. Mó, J.-Y. Salpin, Modeling Interactions between an Amino Acid and a Metal Dication: Cysteine-Calcium(II) Reactions in the Gas Phase, Chempluschem, 78 (2013) 1124-1133.

[18] A.M. Lamsabhi, O. Mó, M. Yáñez, M. Alcamí, J. Tortajada, $\mathrm{Cu}^{2+}$ association to uracil and its thio-derivatives. A theoretical study., ChemPhysChem, 5 (2004) 1871.

[19] A.M. Lamsabhi, M. Alcamí, O. Mó, M. Yáñez, J. Tortajada, Gas-phase deprotonation of uracil-Cu2+ and thiouracil-Cu2+ complexes, J. Phys. Chem. A, 110 (2006) 1943-1950. 
[20] A.M. Lamsabhi, M. Alcamí, O. Mó, M. Yáñez, J. Tortajada, J.Y. Salpin, Unimolecular Reactivity of Uracil-Cu ${ }^{2+}$ complexes in the Gas Phase, ChemPhysChem, 8 (2007) 181187.

[21] C. Trujillo, A.M. Lamsabhi, O. Mó, M. Yáñez, J.Y. Salpin, Interaction of Ca ${ }^{2+}$ with uracil and its thio derivatives in the gas phase, Org. \& Biomol. Chem., 6 (2008) 36953702.

[22] C. Trujillo, A. Lamsabhi, O. Mó, M. Yáñez, J.Y. Salpin, Unimolecular reactivity upon collision of uracil- $\mathrm{Ca}(2+)$ complexes in the gas phase: Comparison with uracil- $\mathrm{M}(+)(\mathrm{M}=$ $\mathrm{H}$, alkali metals) and uracil- $\mathrm{M}(2+)(\mathrm{M}=\mathrm{Cu}, \mathrm{Pb})$ systems, Int. J. Mass Spectrom., 306 (2011) 27-36.

[23] B. Power, V. Haldys, J.Y. Salpin, T.D. Fridgen, Structures of bare and singly hydrated $\mathrm{M}(\mathrm{Ura}-\mathrm{H})(\mathrm{Ura})(+)(\mathrm{M}=\mathrm{Mg}, \mathrm{Ca}, \mathrm{Sr}, \mathrm{Ba})$ complexes in the gas phase by IRMPD spectroscopy in the fingerprint region, International Journal of Mass Spectrometry, 378 (2015) 328-335.

[24] B. Power, V. Haldys, J.Y. Salpin, T.D. Fridgen, Structures of $M(U r a-H)(H 2 O)(n)(+)$ $(\mathrm{M}=\mathrm{Mg}, \mathrm{Ca}, \mathrm{Sr}, \mathrm{Ba} ; \mathrm{n}=1-3$ ) complexes in the gas phase by IRMPD spectroscopy and theoretical studies, Journal of Mass Spectrometry, 51 (2016) 236-244.

[25] S. Guillaumont, J. Tortajada, J.Y. Salpin, A.M. Lamsabhi, Experimental and computational study of the gas-phase interactions between lead(II) ions and two pyrimidic nucleobases: Uracil and thymine, Int. J. Mass Spectrom., 243 (2005) 279-293.

[26] C. Gutle, J.Y. Salpin, T. Cartailler, J. Tortajada, M.P. Gaigeot, Proton transfers induced by lead(II) in a uracil nucleobase: A study based on quantum chemistry calculations, J. Phys. Chem. A, 110 (2006) 11684-11694.

[27] J.Y. Salpin, S. Guillaumont, J. Tortajada, A.M. Lamsabhi, Gas-Phase Interactions Between Lead(II) lons and Thiouracil Nucleobases: A Combined Experimental and Theoretical Study, J. Am. Soc. Mass Spectrom., 20 (2009) 359-369.

[28] B. Power, V. Haldys, J.Y. Salpin, T.D. Fridgen, Structures of $M(U r a-H)(U r a) r$ and $\mathrm{M}(\mathrm{Ura}-\mathrm{H})(\mathrm{H} 2 \mathrm{O})$ rir $(\mathrm{M}=\mathrm{Cu}, \mathrm{Zn}, \mathrm{Pb} ; \mathrm{n}=1-3)$ complexes in the gas phase by IRMPD spectroscopy in the fingerprint region and theoretical studies, Int. J. Mass Spectrom., 429 (2018) 56-65.

[29] J.-Y. Salpin, L. Latrous, V. Haldys, A.M. Lamsabhi, Interactions of Dimethyltin(IV) with Uracil As Studied in the Gas Phase, The Journal of Physical Chemistry A, 122 (2018) 992-1003.

[30] Recent Developments in Mercury Science, Atwood, Springer, Heidelberg, 2006. 
[31] W.F. Fitzgerald, C.H. Lamborg, C.R. Hammerschmidt, Marine biogeochemical cycling of mercury, Chem. Rev., 107 (2007) 641-662.

[32] M. Subir, P.A. Ariya, A.P. Dastoor, A review of uncertainties in atmospheric modeling of mercury chemistry I. Uncertainties in existing kinetic parameters Fundamental limitations and the importance of heterogeneous chemistry, Atmos. Environ., 45 (2011) 5664-5676.

[33] P.A. Ariya, M. Amyot, A. Dastoor, D. Deeds, A. Feinberg, G. Kos, A. Poulain, A. Ryjkov, K. Semeniuk, M. Subir, K. Toyota, Mercury Physicochemical and Biogeochemical Transformation in the Atmosphere and at Atmospheric Interfaces: A Review and Future Directions, Chem. Rev., 115 (2015) 3760-3802.

[34] K.A. Graeme, C.V. Pollack, Jr., Heavy metal toxicity, Part I: arsenic and mercury, J. Emergency Med., 16 (1998) 45-56.

[35] J.F. Risher, P. Tucker, Alkyl Mercury-Induced Toxicity: Multiple Mechanisms of Action, in: P. DeVoogt (Ed.) Rev. Environ. Contam. Toxicol., Springer, New York, 2017, pp. 105-149.

[36] M. Aschner, N. Onishchenko, S. Ceccatelli, Toxicology of Alkylmercury Compounds, in: A. Sigel, H. Sigel, R.K.O. Sigel (Eds.) Organometallics in Environment and Toxicology, Royal Soc Chemistry, Cambridge, 2010, pp. 403-434.

[37] A.A. dos Santos, M.A. Hort, M. Culbreth, C. Lopez-Granero, M. Farina, J.B.T. Rocha, M. Aschner, Methylmercury and brain development: A review of recent literature, J. Trace Elem. Med. Biol., 38 (2016) 99-107.

[38] A.A. dos Santos, C. Lopez-Granero, M. Farina, J.B.T. Rocha, A.B. Bowman, M. Aschner, Oxidative stress, caspase-3 activation and cleavage of ROCK-1 play an essential role in MeHg-induced cell death in primary astroglial cells, Food Chem. Toxicol., 113 (2018) 328-336.

[39] M.J. Moore, M.D. Distefano, L.D. Zydowsky, R.T. Cummings, C.T. Walsh, ORGANOMERCURIAL LYASE AND MERCURIC ION REDUCTASE - NATURES MERCURY DETOXIFICATION CATALYSTS, Accounts Chem. Res., 23 (1990) 301-308.

[40] F. Schurz, M. Sabater-Vilar, J. Fink-Gremmels, Mutagenicity of mercury chloride and mechanisms of cellular defence: the role of metal-binding proteins, Mutagenesis, 15 (2000) 525-530.

[41] A. Elbaz, Y.Y. Wei, Q.A. Meng, Q. Zheng, Z.M. Yang, Mercury-induced oxidative stress and impact on antioxidant enzymes in Chlamydomonas reinhardtii, Ecotoxicology, 19 (2010) 1285-1293. 
[42] C.B. Liu, G.B. Qu, M.X. Cao, Y. Liang, L.G. Hu, J.B. Shi, Y. Cai, G.B. Jiang, Distinct toxicological characteristics and mechanisms of $\mathrm{Hg} 2+$ and $\mathrm{MeHg}$ in Tetrahymena under low concentration exposure, Aquat. Toxicol., 193 (2017) 152-159.

[43] J.W. Sekowski, L.H. Malkas, Y.T. Wei, R.J. Hickey, Mercuric ion inhibits the activity and fidelity of the human cell DNA synthesome, Toxicol. Appl. Pharmacol., 145 (1997) 268-276.

[44] Y. Chang, W.Y. Lee, Y.J. Lin, T. Hsu, Mercury (II) impairs nucleotide excision repair (NER) in zebrafish (Danio rerio) embryos by targeting primarily at the stage of DNA incision, Aquatic Toxicology, 192 (2017) 97-104.

[45] I. Onyido, A.R. Norris, E. Buncel, Biomolecule-Mercury Interactions: Modalities of DNA Base-Mercury Binding Mechanisms. Remediation Strategies, Chemical Reviews, 104 (2004) 5911-5930.

[46] J. Anichina, Z. Dobrusin, D.K. Bohme, Detection of T-T Mismatches Using Mass Spectrometry: Specific Interactions of $\mathrm{Hg}(\mathrm{II})$ with Oligonucleotides Rich in Thymine (T), J. Phys. Chem. B, 114 (2010) 15106-15112.

[47] I.V. Chernushevich, A.V. Loboda, B.A. Thomson, An introduction to quadrupoletime-of-flight mass spectrometry, Journal of Mass Spectrometry, 36 (2001) 849-865.

[48] L. Latrous, J.Y. Salpin, V. Haldys, E. Léon, C. Correia, A. Lamsabhi, Gas-phase interactions of organotin compounds with cysteine, Journal of Mass Spectrometry, 51 (2016) 1006-1015.

[49] R. Prazeres, F. Glotin, C. Insa, D.A. Jaroszynski, J.M. Ortega, Two-colour operation of a Free-Electron Laser and applications in the mid-infrared, European Physical Journal D, 3 (1998) 87-93.

[50] L. MacAleese, A. Simon, T.B. McMahon, J.M. Ortega, D. Scuderi, J. Lemaire, P. Maitre, Mid-IR spectroscopy of protonated leucine methyl ester performed with an FTICR or a Paul type ion-trap, International Journal of Mass Spectrometry, 249 (2006) 14-20.

[51] B. Chiavarino, M.E. Crestoni, S. Fornarini, J. Lemaire, P. Maitre, L. MacAleese, picomplex structure of gaseous benzene-NO cations assayed by IR multiple photon dissociation spectroscopy, Journal of the American Chemical Society, 128 (2006) 12553-12561.

[52] A. Simon, L. MacAleese, P. Maitre, J. Lemaire, T.B. McMahon, Fingerprint Vibrational Spectra of Protonated Methyl Esters of Amino Acids in the Gas Phase, Journal of the American Chemical Society, 129 (2007) 2829. 
[53] G.A. Russell, P. Ngoviwatchai, H.I. Tashtoush, ELECTRON-TRANSFER PROCESSES .43. ATTACK OF ALKYL RADICALS UPON 1-ALKENYL AND 1-ALKYNYL DERIVATIVES OF TIN AND MERCURY, Organometallics, 7 (1988) 696-702.

[54] P. Pyykkö, J.-P. Desclaux, Relativity and the Periodic System of Elements, Acc. Chem, Res. , 12 (1979) 276-281.

[55] W. Liu, R. Franke, M. Dolg, Relativistic ab initio and density functional theory calculations on the mercury fluorides: Is HgF4 thermodynamically stable?, Chm. Phys. Lett., 302 (1999) 231-239.

[56] A. Muñoz-Castro, D.M.L. Carey, R. Arratia-Perez, G.L. Malli, Relativistic effects in bonding and isomerization energy of the superheavy roentgenium ((111)Rg) cyanide, Polyhedron, 39 (2012) 113-117.

[57] M.M. Montero-Campillo, A.M. Lamsabhi, O. Mó, M. Yáñez, Alkyl mercury compounds: an assessment of DFT methods, Theor. Chem. Acc., 132 (2013).

[58] A.D. Becke, Density-functional exchange-energy approximation with correct asymptotic behavior, Phys. Rev. A., 38 (1988) 3098-3100.

[59] Y. Zhao, D.G. Truhlar, A new local density functional for main-group thermochemistry, transition metal bonding, thermochemical kinetics, and noncovalent interactions, J. Chem. Phys., 125 (2006) 18.

[60] J.P. Perdew, DENSITY-FUNCTIONAL APPROXIMATION FOR THE CORRELATIONENERGY OF THE INHOMOGENEOUS ELECTRON-GAS, Phys. Rev. B, 33 (1986) 88228824.

[61] S. Grimme, Semiempirical GGA-type density functional constructed with a longrange dispersion correction, J. Comput. Chem., 27 (2006) 1787-1799.

[62] Y. Zhao, D.G. Truhlar, The M06 suite of density functionals for main group thermochemistry, thermochemical kinetics, noncovalent interactions, excited states, and transition elements: two new functionals and systematic testing of four M06-class functionals and 12 other functionals, Theor. Chem. Acc., 120 (2008) 215-241.

[63] A.D. Becke, Density-functional thermochemistry. III. The role of exact exchange, J. Chem. Phys., 98 (1993) 5648-5652.

[64] C. Lee, W. Yang, R.G. Parr, Development of the Colle-Salvetti correlation-energy formula into a functional of the electron density, Phys. Rev. B, 37 (1988) 785-789. 
[65] X. Xu, W.A. Goddard, The X3LYP extended density functional for accurate descriptions of nonbond interactions, spin states, and thermochemical properties, Proc. Natl. Acad. Sci. U. S. A., 101 (2004) 2673-2677.

[66] C. Adamo, V. Barone, Toward reliable density functional methods without adjustable parameters: The PBEO model, J. Chem. Phys., 110 (1999) 6158-6170.

[67] C. Adamo, V. Barone, Exchange functionals with improved long-range behavior and adiabatic connection methods without adjustable parameters: The MPW and mPW1PW models, J. Chem. Phys., 108 (1998) 664-675.

[68] J.P. Perdew, Electronic Structure of Solids, Akademie Verlag, Berlin, 1991.

[69] H. likura, T. Tsuneda, T. Yanai, K. Hirao, A long-range correction scheme for generalized-gradient-approximation exchange functionals, J. Chem. Phys., 115 (2001) 3540-3544.

[70] S. Grimme, Semiempirical hybrid density functional with perturbative secondorder correlation, J. Chem. Phys., 124 (2006) 16.

[71] K.L. Schuchardt, B.T. Didier, T. Elsethagen, L.S. Sun, V. Gurumoorthi, J. Chase, J. Li, T.L. Windus, Basis set exchange: A community database for computational sciences, J. Chem Inf. Model., 47 (2007) 1045-1052.

[72] Basis Set Exchange (BSE) software and the EMSL Basis Set Library. https://bse.pnl.gov/bse/portal, (2007).

[73] R.F.W. Bader, Atoms in Molecules. A Quantum Theory, Clarendon Press, Oxford, 1990.

[74] C.F. Matta, R.J. Boyd, The Quantum Theory of Atoms in Molecules, Wiley-VCH, Weinheim, 2007.

[75] B.A. Cerda, C. Wesdemiotis, $\mathrm{Li}+, \mathrm{Na}+$, and $\mathrm{K}+$ binding to the DNA and RNA nucleobases. Bond energies and attachment sites from the dissociation of metal ionbound heterodimers, Journal of the American Chemical Society, 118 (1996) 1188411892.

[76] M.T. Rodgers, P.B. Armentrout, Noncovalent interactions of nucleic acid bases (uracil, thymine, and adenine) with alkali metal ions. Threshold collision-induced dissociation and theoretical studies, Journal of the American Chemical Society, 122 (2000) 8548-8558.

[77] M.T. Rodgers, P.B. Armentrout, Cationic Noncovalent Interactions: Energetics and Periodic Trends, Chemical Reviews, 116 (2016) 5642-5687. 
[78] J. Oomens, B.G. Sartakov, G. Meijer, G. von Helden, Gas-phase infrared multiple photon dissociation spectroscopy of mass-selected molecular ions, International Journal of Mass Spectrometry, 254 (2006) 1-19.

[79] C.F. Correia, P.O. Balaj, D. Scuderi, P. Maitre, G. Ohanessian, Vibrational signatures of protonated, phosphorylated amino acids in the gas phase, Journal Of The American Chemical Society, 130 (2008) 3359-3370.

[80] J.Y. Salpin, V. Haldys, S. Guillaumont, J. Tortajada, M. Hurtado, A. Lamsabhi, GasPhase Interactions between Lead(II) lons and Cytosine: Tandem Mass Spectrometry and Infrared Multiple-Photon Dissociation Spectroscopy Study, Chemphyschem, 15 (2014) 2959-2971.

[81] J.-Y. Salpin, V. Haldys, V. Steinmetz, E. Léon, M. Yáñez, M.M. Montero-Campillo, Protonation of methyluracils in the gas phase: The particular case of 3-methyluracil, International Journal of Mass Spectrometry, 429 (2018) 47-55.

[82] J.Y. Salpin, S. Guillaumont, J. Tortajada, L. MacAleese, J. Lemaire, P. Maitre, Infrared spectra of protonated uracil, thymine and cytosine, Chemphyschem, 8 (2007) 2235-2244.

[83] A. Cimas, J.A. Gamez, O. Mo, M. Yanez, J.Y. Salpin, Computational study on the kinetics of the reaction between Ca2+ and urea, Chemical Physics Letters, 456 (2008) 156-161. 
Table 1: Fragment ions observed in the fragmentation of the different $[\mathrm{RHg}(\mathrm{NB})]^{+}$complexes. $\mathrm{m} / \mathrm{z}$ values are given for the ions including the ${ }^{202} \mathrm{Hg}$ isotope.

\begin{tabular}{|c|c|c|c|}
\hline$\left[\mathrm{CH}_{3} \mathrm{Hg}^{+}\right.$ & $\begin{array}{l}\text { Precursor ion } \\
{\left[\mathrm{CH}_{3}{ }^{202} \mathrm{Hg}(\mathrm{NB})\right]^{+}}\end{array}$ & $\begin{array}{l}\text { Fragment ions } \\
{\left[\mathrm{CH}_{3}{ }^{202} \mathrm{Hg}\right]^{+}}\end{array}$ & {$\left[(\mathrm{NB}) \mathrm{CH}_{3}\right]^{+}$} \\
\hline Uracil & $m / z 329$ & $m / z 217$ & $m / z 127$ \\
\hline Uracil-2- ${ }^{13} \mathrm{C}$ & $m / z 330$ & $m / z 217$ & $m / z 128$ \\
\hline Uracil $2-{ }^{13} \mathrm{C}-1,3{ }^{15} \mathrm{~N}_{2}$ & $m / z 332$ & $m / z 217$ & $m / z 130$ \\
\hline Thymine & $m / z 343$ & $m / z 217$ & $m / z 141$ \\
\hline$[\mathrm{n}-\mathrm{BuHg}]^{+}$ & $\begin{array}{l}\text { Precursor ion } \\
{\left[\mathrm{n}-\mathrm{Bu}^{202} \mathrm{Hg}(\mathrm{NB})\right]^{+}}\end{array}$ & $\begin{array}{l}\text { Fragment ions } \\
{\left[\mathrm{n}-\mathrm{Bu}^{202} \mathrm{Hg}\right]^{+}}\end{array}$ & {$[(\mathrm{NB}) \mathrm{n}-\mathrm{Bu}]^{+}[(\mathrm{NB}) \mathrm{H}]^{+}\left[\mathrm{C}_{4} \mathrm{H}_{9}\right]^{+}$} \\
\hline Uracil & $m / z 371$ & $m / z 259$ & $m / z 169 \bigcirc \quad m / z, 113 \quad m / z 57$ \\
\hline Thymine & $m / z 385$ & $m / z, 259$ & $m / z 127 \quad m / z 57$ \\
\hline
\end{tabular}

